\title{
A Comprehensive Review on Sustainable Aspects of Big Data Analytics for the Smart Grid
}

\author{
Vinoth Kumar Ponnusamy ${ }^{1} \mathbb{D}$, Padmanathan Kasinathan ${ }^{2,3} \mathbb{D}^{\mathbb{D}}$, Rajvikram Madurai Elavarasan ${ }^{4}$, \\ Vinoth Ramanathan ${ }^{5}$ (D), Ranjith Kumar Anandan ${ }^{6}$ (D), Umashankar Subramaniam ${ }^{7, *(D)}$, Aritra Ghosh 8 (D) \\ and Eklas Hossain $9, *$ (D)
}

check for

updates

Citation: Ponnusamy, V.K.; Kasinathan, P.; Madurai Elavarasan,

R.; Ramanathan, V.; Anandan, R.K.;

Subramaniam, U.; Ghosh, A.;

Hossain, E. A Comprehensive Review on Sustainable Aspects of Big Data Analytics for the Smart Grid. Sustainability 2021, 13, 13322. https:/ / doi.org/10.3390/su132313322

Academic Editor: Noradin Ghadimi

Received: 1 November 2021

Accepted: 25 November 2021

Published: 1 December 2021

Publisher's Note: MDPI stays neutral with regard to jurisdictional claims in published maps and institutional affiliations.

Copyright: (c) 2021 by the authors. Licensee MDPI, Basel, Switzerland. This article is an open access article distributed under the terms and conditions of the Creative Commons Attribution (CC BY) license (https:/ / creativecommons.org/licenses/by/ $4.0 /)$.
1 Department of Electrical and Electronics Engineering, Sri Krishna College of Engineering and Technology, Kuniamuthur, Coimbatore 641008, India; vinothkumarktp@gmail.com

2 Department of Electrical and Electronics Engineering, Agni College of Technology, Thalambur, Chennai 600130, India; padmanathanindia@gmail.com or padmanathan@nestlives.com

3 Nestlives Privated Limited, Chennai 600091, India

4 Department of Electrical and Electronics Engineering, Thiagarajar College of Engineering, Madurai 625015, India; rajvikram@nestlives.com

5 Department of Computer Science and Engineering, Jerusalem College of Engineering, Chennai 600100, India; captainvinoth@gmail.com

6 Department of Computer Science and Engineering, Lovely Professional University, Phagwara 144411, India; ranjithdr.kumar@gmail.com

7 Department of Communication and Networks, College of Engineering, Renewable Energy Lab (REL), Prince Sultan University (PSU), Riyadh 11586, Saudi Arabia

8 Environment and Sustainability Institute, University of Exeter, Penryn Campus, Penryn TR10 9FE, UK; a.ghosh@exeter.ac.uk

9 Oregon Renewable Energy Center (OREC), Department of Electrical Engineering and Renewable Energy, Oregon Institute of Technology, Klamath Falls, OR 97601, USA

* Correspondence: usubramaniam@psu.edu.sa (U.S.); eklas.hossain@oit.edu (E.H.)

Abstract: The role of energy is cardinal for achieving the Sustainable Development Goals (SDGs) through the enhancement and modernization of energy generation and management practices. The smart grid enables efficient communication between utilities and the end- users, and enhances the user experience by monitoring and controlling the energy transmission. The smart grid deals with an enormous amount of energy data, and the absence of proper techniques for data collection, processing, monitoring and decision-making ultimately makes the system ineffective. Big data analytics, in association with the smart grid, enable better grid visualization and contribute toward the attainment of sustainability. The current research work deals with the achievement of sustainability in the smart grid and efficient data management using big data analytics, that has social, economic, technical and political impacts. This study provides clear insights into energy data generated in the grid and the possibilities of energy theft affecting the sustainable future. The paper provides insights about the importance of big data analytics, with their effects on the smart grids' performance towards the achievement of SDGs. The work highlights efficient real-time energy data management involving artificial intelligence and machine learning for a better future, to short out the effects of the conventional smart grid without big data analytics. Finally, the work discusses the challenges and future directions to improve smart grid technologies with big data analytics in action.

Keywords: smart grid; energy data; big data analytics; energy management systems; Sustainable Development Goals (SDGs)

\section{Introduction}

Energy consumption has drastically increased in recent years due to population growth and rapid urbanization, which eventually resulted in increased carbon emissions. Different countries across the globe strain to provide appropriate services to their citizens 
under essential domains such as public services, water and waste management, building environment and mobility [1,2]. Much research has been conducted early in the life of the smart grid to ensure efficient energy usage and an optimum approach to energy resource management. Smart grid technologies are projected to improve the sustainable supply of power by minimizing energy intensity, energy consumption, and their consequential effects on the environment. However, the pathway by which the smart technology will interact with consumer views and behavior, such that it can ensure long-term sustainability, is yet to be established $[3,4]$. The growth of smart grids has a significant impact on the social and technical aspects of the power supply. In the pursuit of technological advancements, the social aspects of stakeholder impacts (government, private, industry, planner, developer, utility, NOGs and the public community) and the resilience of the smart grid play a major role in achieving Sustainable Development Goals (SDGs) [5].

Understanding the inter-relations among the 17 SDG targets can help in combining different sectoral programmes and in the establishment of coherent cross-sectoral policies to explore possibilities. When investigating the research publications on SDGs, focused research on SDGs was performed in the report titled "The Power of Data to Advance the SDGs", authored by Elsevier and RELX SDG Resource Centre [6]. This report highlights that nearly three million articles have been published on SDG 3 (good health and wellbeing) to date, which tops the other goals in terms of contribution from research publications. In recent years, the effect of global warming was more pronounced, and it is fueled primarily by fossil fuel dependency. It is observed that around $80 \%$ of the electricity and transportation needs are satisfied by the utilization of fossil fuelsThus, there is a pressing need to shift towards clean and affordable energy, which is the core of SDG 7. On analyzing the publications contributing to SDG 7, it was found that around 383,000 articles have been published on SDG 7 (affordable, reliable, modern energy for all), the second highest amount after SDG 3 [1]. Regarding other SDGs, SDG 13 (climate action) secures the third position with 180,000 articles, while SDG 1(zero Poverty) has the least number of publications, with a little over 11,000 related articles. Among these, SDG 7 has a total of $49 \%$ citations in global publications, on average. Though SDG 12 (ensure responsible consumption and production) and SDG 6 (clean water and sanitation) play a vital role in meeting the sustainable goals, SDG 7 has been primarily focused on in the research. As per the report, $13 \%$ of the global population lacks access to modern electricity [6].

Different global nations, especially China, India, Germany, the United Kingdom and many developing countries, focus on the research that supports SDG 7 for their economic growth, efficient utilization of resources and energy production. The volume of research contribution towards SDG 7 increased up to 9.1\% CAGR from 2015 in comparison with other SDGs, which have achieved only 3.5\% CAGR. A total of $57.2 \%$ of publications are contributed by high income generating countries. The highest number of research contributions towards SDG 7 is from China, or, in other words, more than 167,700 publications $(57.2 \%)$ are from China, while the lowest number of publications are from India. The collaborative research on SDGs contributes about $23 \%$, whereas there is an increase in Field-Weighted Citation Impact (FWCI) for SDG 7 research every year [6,7]. This research aims at sharing knowledge and research findings on how the smart grid's efficiency can be increased with the deployment of big data analytics. The major purpose of this research paper is to produce a substantial research contribution in the area of big data analytics for smart grid data to fulfil SDG 7, so that dependable, clean and affordable energy can be provided to all.

\subsection{Research Motivation}

The motivation behind the implementation of big data analytics in the smart grid to achieve SDG is listed herewith: (1) Integration of renewables and electric vehicles into the smart grid; (2) Enhancement of consumer-side distributed generation for economic improvement; (3) Increased energy efficiency with demand-side response and energy management; (4) Promotion of involvement of better energy management practices and 
facilitation of novel tools and business models for efficient power utilization, and (5) Ameliorating the quality of life for stakeholders through effective services. The Sustainable Development Goals were proposed by the UN to be achieved by 2030, and they comprise 17 goals and 169 targets [8]. The selection of suitable indicators and proper data gathering from different resources helps to achieve Sustainable Development Goals $[9,10]$.

All the goals are inter-connected with social, economic, technical, policy and environmental aspects of sustainable development, which altogether ensures a better quality of life. With modelling and implementation of big data techniques as well as efficient communication technology, governments can enable better access and management of energy information via the smart grid. Further, both stakeholders and governments across the globe should participate in achieving SDG 7. ICT and big data analytics can enhance the monitoring and measurement of smart grid development towards the SDGs. ICT, in a smart grid environment, enables better communication between the utilities and consumers in terms of rendering energy information for decision-making purposes. Furthermore, it enables policy makers to successfully state the economic, social and technical advancements. Table 1 analyses the motivation for the research and outlines the work reviewed with technical, economic, social, policy and environmental factors to achieve SDG 7 [11].

Table 1. Investigation of research motivation and the outline of work reviewed with technical, economic, social, policy and environmental factors to achieve SDG.

\begin{tabular}{c} 
Motivation \\
\hline $\begin{array}{c}\text { Enhance large-scale renewable energy production } \\
\text { and the integration of electric vehicles with } \\
\text { smart grid }[4,10,11]\end{array}$
\end{tabular}
smart grid $[4,10,11]$

\section{Outlining of Work}

Economic: New infrastructure for the integration of renewable and electric vehicle-based energy storage.

Social: Offers diversified energy supply and lessen the dependence on fossil fuels. Technical: Suitable converters for the integration of different renewable sources with the existing grid and monitoring.

Policy: Novel regulatory systems and market designs are needed to encourage energy storage options.

Environmental: Decrease the emission of greenhouse gas and prevent the pollution of land and water.

Economic: Reduction in electricity cost and revenue generation for consumers who use smart metering.

Social: Reduction in electricity losses along transmission and distribution lines and less dependency upon public utilities.

Improvement of distributed generation $[12,13]$

Technical: Allow the incorporation of smart metering and communication to manage power flow and reduce power outages.

Policy: Regulations to access energy and assets connected with the distribution grid. Environmental: Deliver clean, reliable power to additional customers.

Economic: Improve the efficiency of renewable energy.

Social: Equalize energy consumption and balance power generation.

Technical: Implementation of data feedback systems and monitoring devices to reduce grid vulnerabilities.

Enhance the efficiency through demand-side response and energy management [14,15]

Policy: Standards and regulatory frameworks to access smart metering information and sensor data.

Environmental: Reduce the consumption of fuel in energy production by load shifting and pollution reduction.

Economic: Usage of real-time pricing reduces the cost incurred upon electricity utilization.

Social: Improved energy efficiency to offer better services to consumers so as to provide comfort and wellbeing.

Increase the involvement of better practices; innovate novel tools and business models for efficient power utilization $[16,17]$

Technical: Implementation of demand-side management and energy management related tools to ensure better communication between utilities and consumers.

Policy: Network visualization and support guidelines coupled with best practices.

Environmental: Optimized asset utilization and efficient operation to reduce emissions.

Economic: Creation of new jobs and improvement in the quality of people's lives. Social: Revolution in industrial and energy sectors leading to the modernization of equipment for efficient grid usage.

Enhancement of Quality of Life for all stakeholders [18,19]
Technical: Enhancement in transmission and distribution protection, access to quality power with power quality monitoring, sufficient and continuous power.

Policy: Enforcement of standards and smart living regulations.

Environmental: Minimal impact upon land, air and water 


\subsection{Review Methodology}

The tremendous growth of smart grid technologies towards the achievement of sustainable development goals results in a series of scientific and engineering challenges. These problems mandate the application of ingenious research from both academic institutions and research laboratories, which should satisfy the new protocols, architectures and services. The main aim of this research is to collate the efforts of scholars, engineers, researchers, professors and administrators towards the development of state-of-the-art technologies and ideas to significantly enhance smart cities and achieve the SDGs. The current research paper gives a detailed view of smart grids and a workflow that integrates smart grids, big data analytics and digital transformations, which altogether helps in achieving the sustainability goals.

\subsubsection{Literature Review}

The proposed work reviews the studies by searching for the ways in which big data analytics in the smart grid facilitate the achievement of SDGs through the following investigation questions.

Q1. What are the existing research topics in smart grid energy management systems?

Q2. Who are energy data contributors related to smart grid energy systems?

Q3. What are the aesthetic and operational hurdles faced in the implementation of the smart grid?

Q4. How will big data analytics assist energy management systems to reach sustainable goals in the future?

Q5. What is the future of smart grid research to attain sustainable goals?

By organizing the study with a review on big data-determined smart grid management, the literature review, linked with smart grid technology, evaluated the existing state-of-theart smart grid in electric big data viewpoints. Further, the work is followed by conclusions for the research that aim at achieving sustainable goals. Figure 1 shows the flow of research work. The papers used for review were sourced from standard databases such as Scopus, SCI journals, etc., based on the suitability of the research topic. The papers were sorted based on title and keywords related to the concept that contributes to the smart grid. Previous research papers were segregated based on the domain of smart cities, smart energy, big data analytics in the smart grid and the contribution of the smart grid towards sustainable goals. The works referred to in this study were published in the range of 2017 to 2021. Most of the review's contribution involves the recent technologies between 2019 and 2020.

\subsubsection{Background Methodology}

Table 2 compares the research works conducted upon big data analytics in smart grids to highlight the difference between existing works and the current research work. These works concentrate on tools, software and hardware requirements for big data analytics, challenges and opportunities. The review discusses power generation side management, microgrid and renewable energy management, asset management, collaborative operation and demand-side management (DSM) [20,21]. The studies conducted earlier $[20,22]$ focus on energy management, while one of the papers [23] focuses on forecasting of load and renewable energy, and other works [24,25] conducted studies on the communication technologies and big data analytic tools in the smart grid. However, these research studies did not concentrate on the motivation to achieve sustainable goals. Further, the works were not reviewed in line with technical, economic, social and environmental factors. 


\section{TARGETING RESEARCH METHODOLOGY}
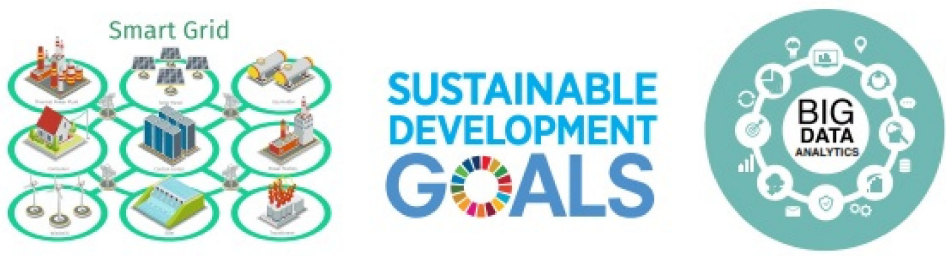

\section{Literature review}

1 Summarize existing research and defining the research themes on smart grid

\section{Background Methodology}

2 Explore the holistic background of smart grid and different big dato analytics for grid operations towards achieving the Sustainable Development.

\section{Role of Big Data Analytics in Smart Grid}

3 Analyse the Smart Grid Architecture with the big data analytics operations

from the existing grid data. Recommending the new architecture ideology for the Sustainable Development.

Achievement of sustainability with grid smartization and efficient

4 management of data with big data analytics in social, economic, technical and policy aspects

\section{Challenges and future directions in implementation of smart grid system}

Figure 1. Research methodology performed to achieve sustainable goals with big data analytics in the smart grid.

Table 2. A comprehensive review of the studies conducted so far on smart and big data analytics.

\begin{tabular}{|c|c|c|c|c|c|c|c|c|}
\hline \multirow[b]{2}{*}{ Authors } & \multicolumn{8}{|c|}{ Topics Discussed } \\
\hline & $\begin{array}{l}\text { Grid Data } \\
\text { Sources and } \\
\text { Data Com- } \\
\text { munication } \\
\text { Technologies }\end{array}$ & $\begin{array}{c}\text { Tools for } \\
\text { Big Data } \\
\text { Analytics } \\
\text { Method }\end{array}$ & $\begin{array}{l}\text { Software and } \\
\text { Hardware } \\
\text { Require- } \\
\text { ments for } \\
\text { Big Data } \\
\text { Analytics in } \\
\text { Smart Grid }\end{array}$ & $\begin{array}{l}\text { Challenges } \\
\text { and Oppor- } \\
\text { tunities }\end{array}$ & $\begin{array}{c}\text { Role of } \\
\text { Big Data } \\
\text { Analytics } \\
\text { in Energy } \\
\text { Management }\end{array}$ & $\begin{array}{c}\text { Motivation } \\
\text { to Achieve } \\
\text { Sustainable } \\
\text { Goals }\end{array}$ & $\begin{array}{c}\text { Is the Work } \\
\text { Reviewed with } \\
\text { Technical, } \\
\text { Economic, } \\
\text { Social and } \\
\text { Environmental } \\
\text { Factors? }\end{array}$ & $\begin{array}{c}\text { Forecasting, } \\
\text { Renewable, } \\
\text { Load and } \\
\text { Non-Technical } \\
\text { Loss }\end{array}$ \\
\hline Zhou et al. [20] & No & Yes & Yes & No & Yes & No & No & No \\
\hline Syed et al. [21] & No & Yes & Yes & No & No & No & No & No \\
\hline Bhattari et al. [22] & No & No & No & Yes & Yes & No & No & No \\
\hline Zhang et al. [23] & Yes & No & Yes & No & No & No & No & Yes \\
\hline Ghorbanian et al. [24] & No & Yes & No & Yes & No & No & No & No \\
\hline Daki et al. [25] & Yes & No & Yes & No & No & No & No & No \\
\hline
\end{tabular}




\subsubsection{Role of Big Data Analytics in the Smart Grid and Achieving Sustainable Goals}

This review establishes the current state-of-the-art big data analytic techniques for the smart grid to attain sustainability. Firstly, economic, social, technical and environmental aspects are discussed against the smart grid and big data analytics towards the attainment of sustainable goals. The information on the smart grid and big data generated from smart grids is summarized. The next section focuses on the role of big data analytics in the smart grid and the process involved for achieving sustainable goals. The achievement of sustainability with upgrading the grids to smart grids and efficient management of data with big data analytics in social, economic, technical and policy aspects is discussed. This research also discusses how big data analytics in the smart grid can help in attaining SDG with real-time implementation, using artificial intelligence and machine learning algorithms. Further, the work discusses the inter-relationship of different SDG goals. Finally, the work focuses on future challenges and directions for the implementation of big data analytics in the smart grid.

\section{Smart Grid}

The smart grid integrates both the behaviours as well as the actions of overall users, such as generators, consumers and generator-consumers in a cost-efficient manner. Due to this integration process, less power loss occurs and high-quality power output is produced, as a result of which the power system remains cost-efficient and sustainable. In addition, the system is secured with safety measures. New products, technologies and services with regards to control, communication, intelligent monitoring and self-healing are nowadays incorporated in smart grids. These entities bring different benefits, such as easy connection and facilitation of operations for generators of all sizes and technologies. Here, consumers play a vital role in the optimization of system operations, while they are also aware of the information about the systems. Further, the load demand can be effectively optimized, which can significantly reduce environmental pollution in the whole electricity supply system. In addition to this, customers can perform appropriate maintenance, ameliorate existing high system levels and ensure reliability, quality and security of supply [26].

Most of the definitions converge at a single element, i.e., the smart grid has digital processing and communications, due to which the data flow control and information management prevails as the crux of the system. The smart grid has different potentials, thanks to the deeply-integrated application of digital technology in power grids. The information which is integrated with the new grid remains the critical issue when it comes to smart grids. Today's electric utilities undergo three levels of transformation, which form the core principles of the smart grid, such as improvement of infrastructure, a strong grid and the addition of a digital layer. Further, business process transformation is required to capitalize on the investments made in smart technology. Electric grid modernization works that have been carried out earlier in substations and distribution automation are now included in the smart grid concept itself. The smart grid corresponds to the complete set of current as well as proposed responses to challenges encountered in power supply. With the involvement of different factors with competing taxonomies, there is no specific universal definition available so far for smart grids. Challenges encountered during the integration of renewable energy resources into smart grid systems are addressed for the virtualization of the projected grid architecture. Both innovative as well as robust modelling of different components are required. The integration of novel technologies into the conventional grid is critical, and the implementation of smart grid architectures with RESs should be incentivized [27].

The flow of power generated from different energy sources into the grid makes the energy system highly robust and adaptive, especially when it comes to matching supply and demand. When global infrastructure needs to be upgraded, a seamless supply of electricity plays a central role. The modern electrical power system bolsters the present as well as future digital economy, and it also buttresses the development of safety, health and national security. Our energy infrastructure encounters a lot of threats, in the form of 
nature (extreme weather conditions), cyber-attacks (for instance, hackers), physical attacks (terrorism), etc. In this situation, smart grids improve the sustainability of renewable energy resources. These smart grids contribute towards energy conservation and cost-efficient energy management, which finally add value to a clean energy environment [28,29]. Data management systems, sensors, smart meters and appropriate monitoring systems are part of the process of smart grids. Smart grid and, subsequently, the smart metering technologies, is the need of the hour to achieve a sustainable electrical utility. Here, an information system network is required so that it ensembles all substations in coordination with user facilities as well as utilities. However, one should be equipped with high-end system analysis as well as trustworthy communication systems that serve as the pillars of smart grid visibility. Remote communication management among various head-end systems, where the connection is established with smart meters, is one of the primary challenges that require attention. Smart meters are intelligent measurement systems that consist of a smart meter gateway, digital electricity meter and a communication module. In this regard, one can perform real-time estimation of both consumption as well as production characteristics of power, even at individual installations. For instance, an uninterrupted transfer of network status data occurs at the data network, where it is managed, bundled and again transferred to an energy supplier through gateway administrator. Here, the role of gateway administrator is played by meter operator or, otherwise, a local network operator themselves. The smart grid, when implemented successfully, is predicted to solve the confinements experienced in the delivery and distribution of power [29,30]. In the process of achieving this visionary objective, the stakeholders are advised to strategize their utilities and state-level policies.

When distributed energy resources such as energy storage systems, solar photovoltaic and combustion engines are integrated, various advantages can be reaped, which include reduction in system losses and optimized energy consumption as well as economic savings, enhanced resilience, improved power quality and customer participation. In this scenario, the existing grids cannot be coordinated or managed via Distributed Energy Resources (DERs). Electricity flow can be controlled in every household, or even for every smart appliance of the customer. Thus, it can be inferred that the smart grids of the 21st century are set to change grid dynamics drastically, potentially giving rise to the 'Grid of Things', similar to the concept of the 'Internet of Things'.

\subsection{Big Data from Smart Grid Operations}

Digital transformation enables the integration of renewable energy, sustainable communities and growth of industries, which altogether results in better and more coordinated economic growth. A combination of both grid visualization and grid management aids in making predictive decisions and better situational awareness [31]. Further, smart grids introduce end users into the energy trading system, rather than keeping them as a mere consumer, through demand response, Electric Vehicle (EV) charging, self-produced distributed generation and energy storage. Accordingly, an enormous amount of data gets generated based on the involvement of various stakeholders, which opens multiple data analytics market possibilities surrounding the smart grid [32]. It is important to ensure big data management to leverage the data generated by these processes to gain insights, as shown in Figure 2.

\subsubsection{MV and LV Grid Planning}

At the time of modernizing smart grids, grid planning is crucial, since the grid connection integrates both low as well as high voltage renewable energy sources. When renewable energy sources and electric vehicles are integrated with low voltage grids, it may increase the voltage's volatility [33]. A comprehensive database should be available with information about the cause for voltage volatility. This information would be made available to the distribution system operator for planning. Further, load forecasting should be critically analysed with the available grid transmission and generation data to enumerate 
a realistic estimate of load distribution. The ultimate goal is to produce sustainable power through load balancing [34].

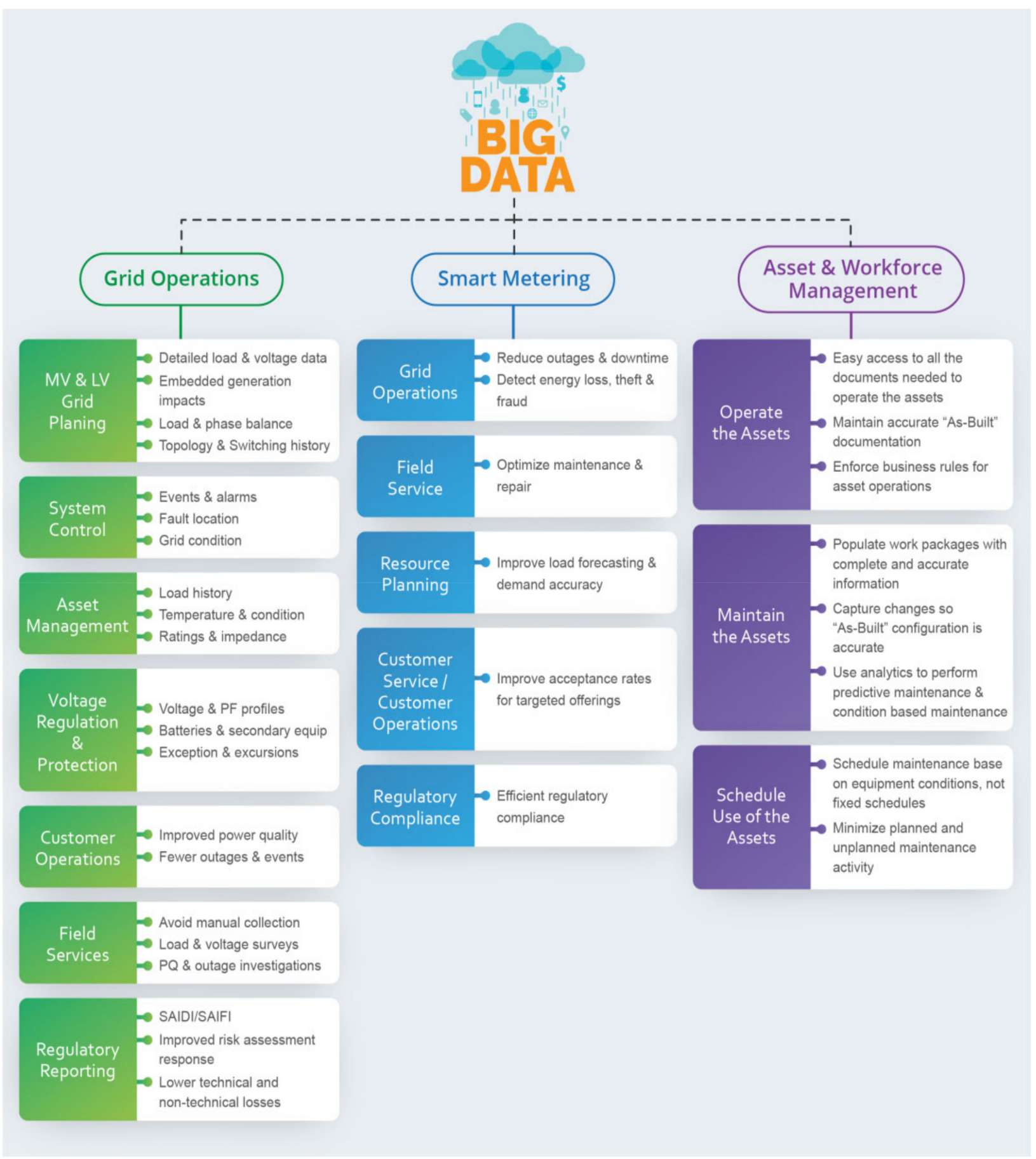

Figure 2. Smart grid big data generated from grid operations, smart metering and asset and workforce management.

\section{Impact of Embedded Generation}

The networks are designed in such a way that the voltage increases when there is a reverse flow of power from embedded generators. When an embedded generator is connected with a weak network or when power is forced to flow via a weak network, the losses may increase. In numerous cases, there is a positive contribution from embedded generators in terms of reduced volume of network technical losses. During maximum generation using minimal load, the embedded generators may increase the loading levels 
of transformers and transmission lines. Hence, the generated data can be utilised by control centres for effective grid control $[35,36]$.

Load \& Phase Balance

Unbalanced voltage may occur when phases, attached to the grid, are not equally utilized. This grid imbalance may eventually result in impaired control equipment, impaired regulation equipment, uneven loading of the transformers, reactive power costs and uneven motor operation (losses, wear). Grid imbalance occurs due to disruption in the requirements of utility companies $[37,38]$.

\subsubsection{Asset Management}

When there is an asset management system in place that works according to data analytics and condition-based maintenance, the chance for equipment failure risks is minimal. Further, it also maximizes the equipment's life expectancy. The results of effective asset management can is reflected in reliable service, reduced emissions, lessened costs and increased efficiency for end users [39].

\subsubsection{Voltage Regulation and Protection}

Across the globe, geographical conditions vary from one country to another. To provide reliable and regulated voltage for the consumer, proper voltage regulation becomes imperative. After integrating with the smart grid, batteries play a crucial role in mitigating the challenges of power quality through electric vehicles. The batteries' selection is an important parameter for better voltage regulation when connected with the smart grid. To construct efficient renewable energy storage systems, attention should be focused on desirable qualities including cycle life, flexible sizing and excellent renewability categorised batteries $[40,41]$.

\subsubsection{Customer Operation}

Harmonics, voltage sags and power interruptions are predominant power quality issues faced by the consumer, who incurs a heavy economic loss. There are numerous challenges associated with poor power quality in the industry. Software bugs, COVID-19 pandemic outbreak, temperature, radio frequency, equipment EMI, temperature, operator errors, humidity and radio frequency interference are some of the challenges faced by consumers in terms of power quality. It is important to monitor the data for power quality to assess the performance of the network [42].

\subsubsection{Field Services}

Field services play a vital role in effective operations, investment plans and forecasting maintenance. The data collected from field instruments are collated at the control room to optimize the plants, equipment, people, assets, etc., during the life cycle of every asset.

\subsubsection{Customer and Utility Operations}

When using smart meters, electricity consumers or end users gain better benefits due to increased accuracy in billing and fast and flexible service. Smart meters receive the data and update them to consumers. Further, it also saves the interval load data to raise an invoice for the customer based on their usage. Customers can save costs by reducing their usage during peak periods based on real-time information. Likewise, the utilities that look for cost-cutting can serve their consumers in a better way and raise their efficiency [43].

\subsubsection{Regulatory Compliance}

There is a need to establish a legal foundation for data collection as well as the processing of energy consumption data collected from consumers. This is to ensure that the customer's privacy is respected and protected. According to regulatory compliance, energy consumption data recorded by smart meters are tagged as personal data. There must be 
regulations for the data collected from the smart grid with regards to the performance of standards for making and keeping appointments, a prompt fixture of faulty meters and reestablishment of supply after the debt is paid off. These regulations help the smart grid system to be efficient $[44,45]$.

\subsection{Asset and Workforce Management}

Asset and workforce management enhance the operation and maintenance of utilities, while the consumers and stakeholders of the smart grid are invoked to improve the efficiency and economy. In addition to these, it also ensures secure billings, information and subsidy benefits [46].

\subsubsection{Operation of the Assets}

The smart grid's assets generate huge volumes of multifaceted data from hardware and software systems. These data are utilized to integrate renewable, transmission and distribution equipment, used for power quality, ICT, storage devices and electric vehicle applications. All these data can be easily accessed to operate the assets. Data collection patterns and plans are important documents and are pointed out as "As-Built" documents that support the functioning of assets, for which verification is important to maintain accuracy [47].

\subsubsection{Asset Maintenance}

The smart grid involves different operations and measurements in generation, transmission and distribution. These real-time data are acquired completely and accurately from different stakeholders. These data are used in analytics platforms to perform predictive maintenance and condition-based maintenance [48]. Policy makers examine the utilities to formulate business rules for asset operations that successfully handle metering of the data and operations [47,49].

\subsubsection{System Control}

A combination of both intelligent alarm processors and optimal fault identification provides an overview of defects and their whereabouts. Smart grids can be secured with various factors, such as the optimization of fault location, quick response methods and protective relaying, based on new communication techniques [50,51]. The owner of an asset must proactively take actions to increase the asset's availability, optimize the costs incurred in asset management and mitigate the risks that potentially threaten the operations. With utility asset management, companies can observe the usage, age and maintenance history as well as other such variables of an asset [52]. One must record the data with regards to voltage, power factor, recharge life rating and battery discharge level to ensure voltage regulation and protection [53].

\subsubsection{Regulatory Reporting}

When a smart grid is regulated under optimum conditions, it increases the economy of the asset through an efficient electric network. This results in effective management of transmission as well as distribution networks that in turn improve network security. There is a provision available in smart grids to generate regulatory reports, through which serious threats can be identified and prevented. In this way, technical and non-technical losses can be mitigated [54].

\subsection{Big Data from Smart Metering}

\subsubsection{Grid Operations}

At the time of using smart meters, the entire grid gains proficiency via accurate meter reading, power outage response and the detection of energy thefts. There is no need to conduct onsite visits to record the meter reading. The energy sector in India faces a common issue, i.e., power theft, which can be minimized or even eliminated with smart 
meters [55]. When using smart meters, the place where energy is utilized can be tracked and real-time monitoring of power usage ensured. This, in turn, enhances the transparency of the system. Further, power outages can also be reduced by smart meters. These smart meters enable the power distributors to forecast power demand fluctuations and respond quickly and autonomously. In this manner, the distribution and reliability of the energy provider are improved [56].

\subsubsection{Field Service}

In the case of smart meters, one needs to manage field logistics and a set of reports upon data collection, reporting, processing, configuration, maintenance, installation, meterreading and outage response daily. The technicians tend to standby round the clock to tackle emergency calls. However, they may not be required to address general repairs and regular maintenance. When it comes to smart meters in the smart grid, both maintenance and repair become easy.

\subsubsection{Resource Planning}

Smart meters control energy consumption and perform real-time monitoring. These actions produce huge volumes of measurement data that can be utilized in the prediction of load demands. Since smart meters track electricity consumption patterns from time to time, these data are highly helpful in enhancing the load forecasting functions.

\subsubsection{Scheduled Use of Assets}

Schedule maintenance in the smart grid is based on equipment conditions, and not based on a fixed schedule. Proper scheduling of assets in the smart grid tends to reduce both planned and unplanned maintenance activity, which in turn reduces the cost involved in operations [57].

\section{Role of Big Data Analytics in Smart Grids}

With the increase in distributed generation, data-based customer interface and alternative energy sources, the utilities are coordinating with each other to produce an information-based digital economy [58]. Today's energy sector faces various challenges such as delayed outage response times, theft of information and cyber security, integration of large-scale distributed energy generation and energy storage, implementation of electric vehicle charging and smart grid business models. The digitized grid allows excellent control and intelligent monitoring capabilities. In addition to the above merits, smart grids can diminish the loss of power and data thefts by altering real-time electrical parameters such as phase, power, current and voltage. It can also identify the source of theft by tracking the location and pointing out the exact source of theft $[59,60]$.

The taxonomy of big data analytics for the smart grid is shown in Figure 3. The figure showcases the sources of big data, components of big data analytics, big data-enabling technologies, functional elements in a smart grid and the types of big data analytics. On the other hand, Figure 2 shows different big data sources of smart grids. Both system components and big data technologies of big data analytics, utilized in the smart grid, are detailed under Section 3.2 and Table 3. The functional elements and predictive analyses that are performed in the smart grid yield knowledgeable insights through which better, faster and more informed decision-making can be achieved on the smart grid, as detailed under Section $3.1[61,62]$.

\subsection{Key Issues in Smart Grids and the Outcomes of Big Data Implementation}

Traditional grid systems do not have the facility for data acquisition and monitoring. They also lack the potential to handle real-time processing of huge volumes of structured as well as unstructured datasets in the energy sector, which can confuse analysts. 


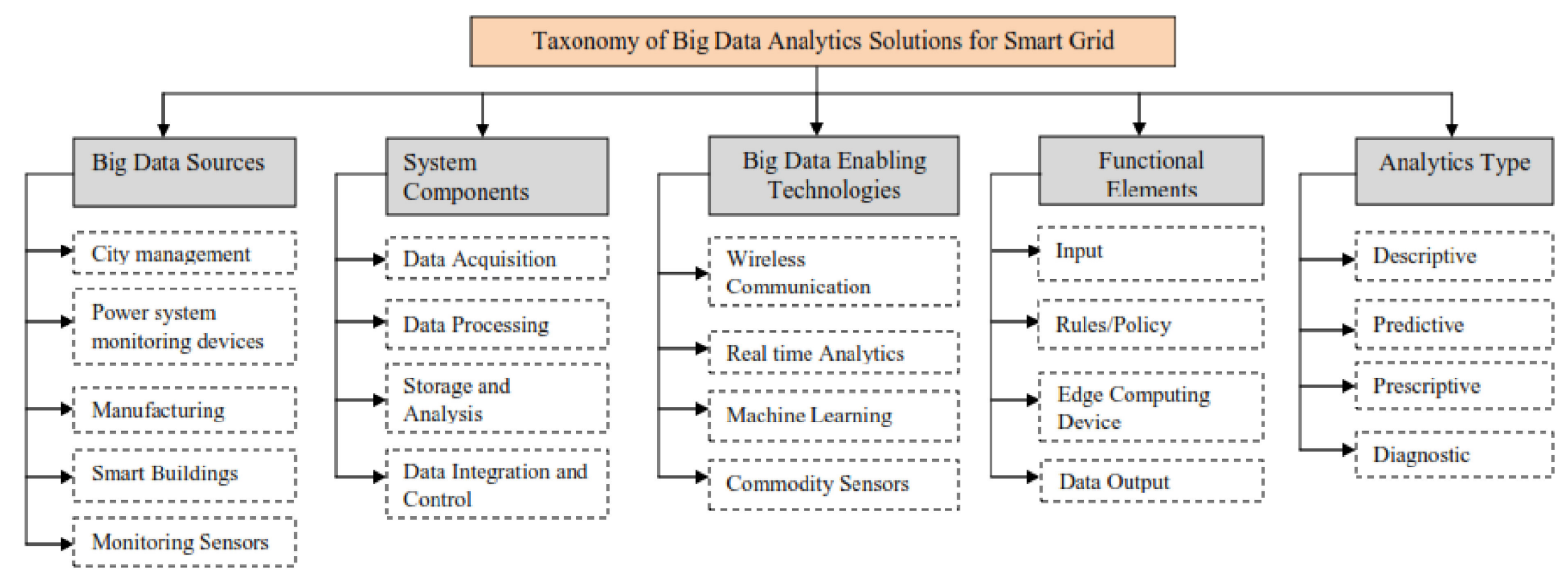

Figure 3. Taxonomy of big data analytics for the smart grid.

Table 3. Review questions and the role of big data analytics.

\begin{tabular}{|c|c|c|c|}
\hline Q.No & Question & Task & Process \\
\hline Q1 & What action is taken? & Supervision and execution & $\begin{array}{l}\text { According to the demand response, power } \\
\text { generation and peak load management offers } \\
\text { incentives to the consumers }\end{array}$ \\
\hline Q2 & What is occurring? & Innovation and Investigation & $\begin{array}{l}\text { Monitoring the grid status, analysing customer } \\
\text { usage, detecting energy theft and directing the data } \\
\text { across the enterprise. }\end{array}$ \\
\hline Q3 & What could occur? & Forecasting & $\begin{array}{c}\text { Forecast equipment failure and avoid outage, excess } \\
\text { loads on the grid before they occur and customers } \\
\text { suitable for demand response offerings. }\end{array}$ \\
\hline Q4 & Why did it occur? & Monitoring and Analysis & $\begin{array}{l}\text { Monitor the performance and status of the smart } \\
\text { grid components data and analyse the assets during } \\
\text { operations through reports. }\end{array}$ \\
\hline
\end{tabular}

These copious data can be handled through big data analytics easily, predictive analysis especially can aid in better and faster decision-making, which can be supportive to achieve strategic business objectives, as shown in Figure 4 [61-64]. Dynamic and efficient energy management is possible in smart grids, with the help of big data analytics and better grid visualization, as shown in Figure 5 . This shows that the smart grid, coupled with big data, provides a lot of advantages in terms of power generation optimization in power plants, improvement of customer interaction, optimization of emergency response to outages in domestic coverage, optimization and planning of transmission and smart distribution from transmission and distribution sides, and efficient involvement of DERs as well as electric vehicles, from the commercial side [65]. Efficient energy utilization with greater preference to renewable energy is enabled by close monitoring of data and information that can offer proficient schedules through a smart meter. Further, power quality devices with efficient ICT can achieve suitable power generation and reduce environmental hazards [66-68]. Figure 6 also depicts the involvement of dynamic and modern data analytics coupled with optimum and high-performance computing with efficient data network management for the smooth functioning of smart grids [69-71]. This model can also predict the challenges and opportunities present in the energy sector and utilities. It also produces knowledgeable cognizance, good situational awareness and predictive decisions. There occurs a dual-flow transfer of data and power in smart grids, i.e., between consumers and suppliers. This enables power optimization with regards to power sustainability, energy efficiency and reliability. Energy management is directly related to environmental preservation and economic growth. Better optimization and energy management by utilities and consumers contribute towards the achievement of SDGs [72-74]. Therefore, both of the stakeholders (consumers and producers) actively 
participate in energy market trading, which results in dynamic energy management with load forecasting and renewable energy production.

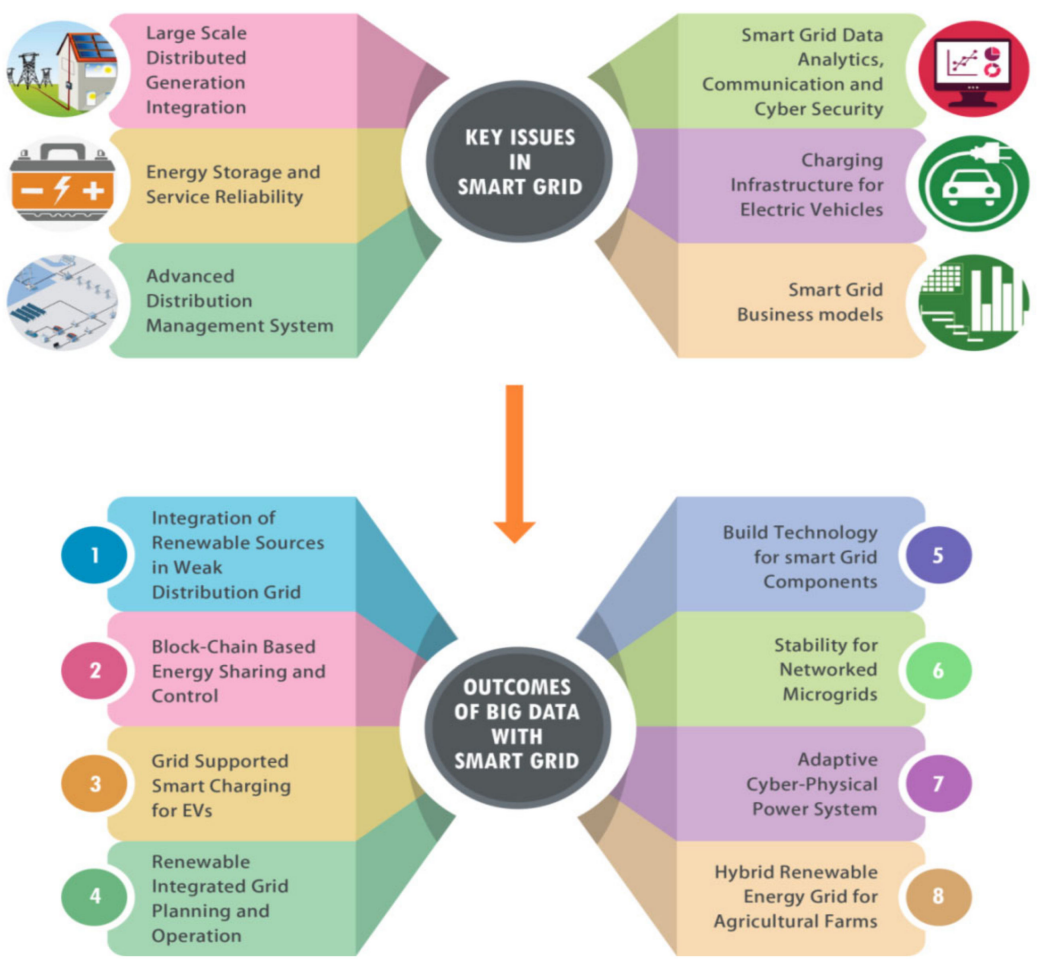

Figure 4. Key issues in smart grids and outcomes of big data implementation.

The achievement of SDG 7 depends on the involvement of socioeconomic and technical aspects of the energy sector. Many perspectives are considered in a big data-enabled smart grid system to attain socioeconomic development. Regulatory and government policies, governing systems, implementation of new architecture and finance are the cardinal factors to be considered while implementing sustainability practices [54,75]. Through big data analytics, efficient energy data management is feasible, which aids in the achievement of SDGs. However, the concerns with regard to electric vehicles, integration of energy storage with existing grid, intelligent metering, cyber security, application of analytical software, surveillance monitoring and digital mapping are under the control of government organizations in most countries. Figure 6 showcases the outcomes achieved through successful big data analytics in terms of smart grid management with data from Energy Management Systems (EMS), Distributed Management System (DMS), Advance Metering Interface (AMI) and Geographical Information system (GIS). These systems offer better surveillance and data monitoring for analytics and decision making in the smart grid to attain sustainable goals [76-81].

Smart grids have different applications installed, such as outage management, energy management system, fault protection, distributed asset monitoring, EV smart charging, integration of weather data, dynamic voltage control, centralized capacitor bank control, automated feed reconfiguration and distribution, as well as substation automation with advanced sensing. In addition to these, provisions such as load forecasting, demand response, shifting and advanced demand maintenance are also installed. The smart grid enables provisioning for the identification of electricity theft, prepaid customer plans, mobile workforce management and remote meter reading [82]. The smart grid system is an automated and self-sustainable electricity network system that can control and monitor the smart meters and can analyse the data in the supply chain. This system can rapidly resolve the issues and reduce the manpower involved in a safe, reliable and sustainable manner. Furthermore, it also provides quality electricity to all of its consumers simultaneously. 


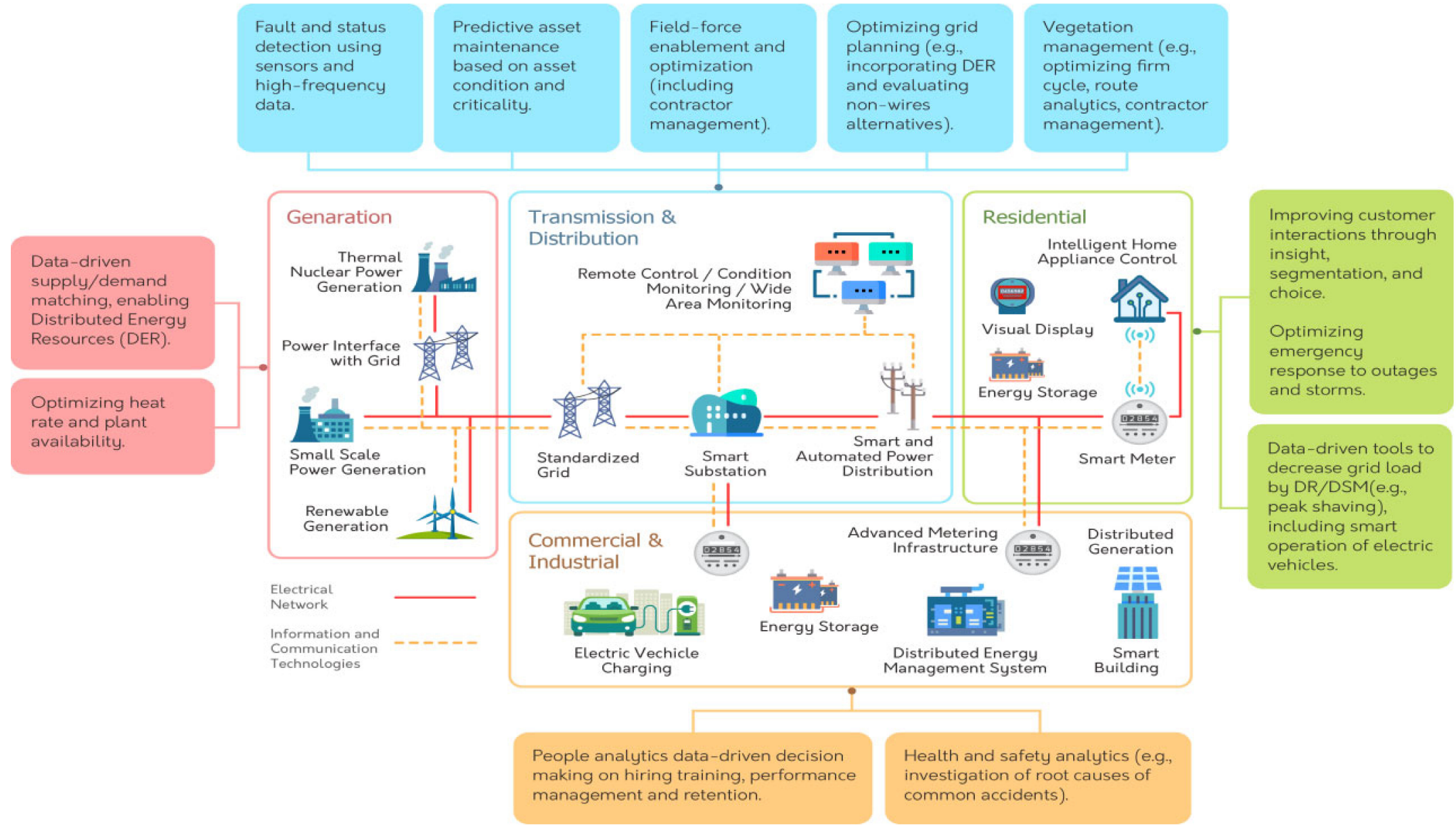

Figure 5. Analytics strategy development model with big data and better grid visualization. 


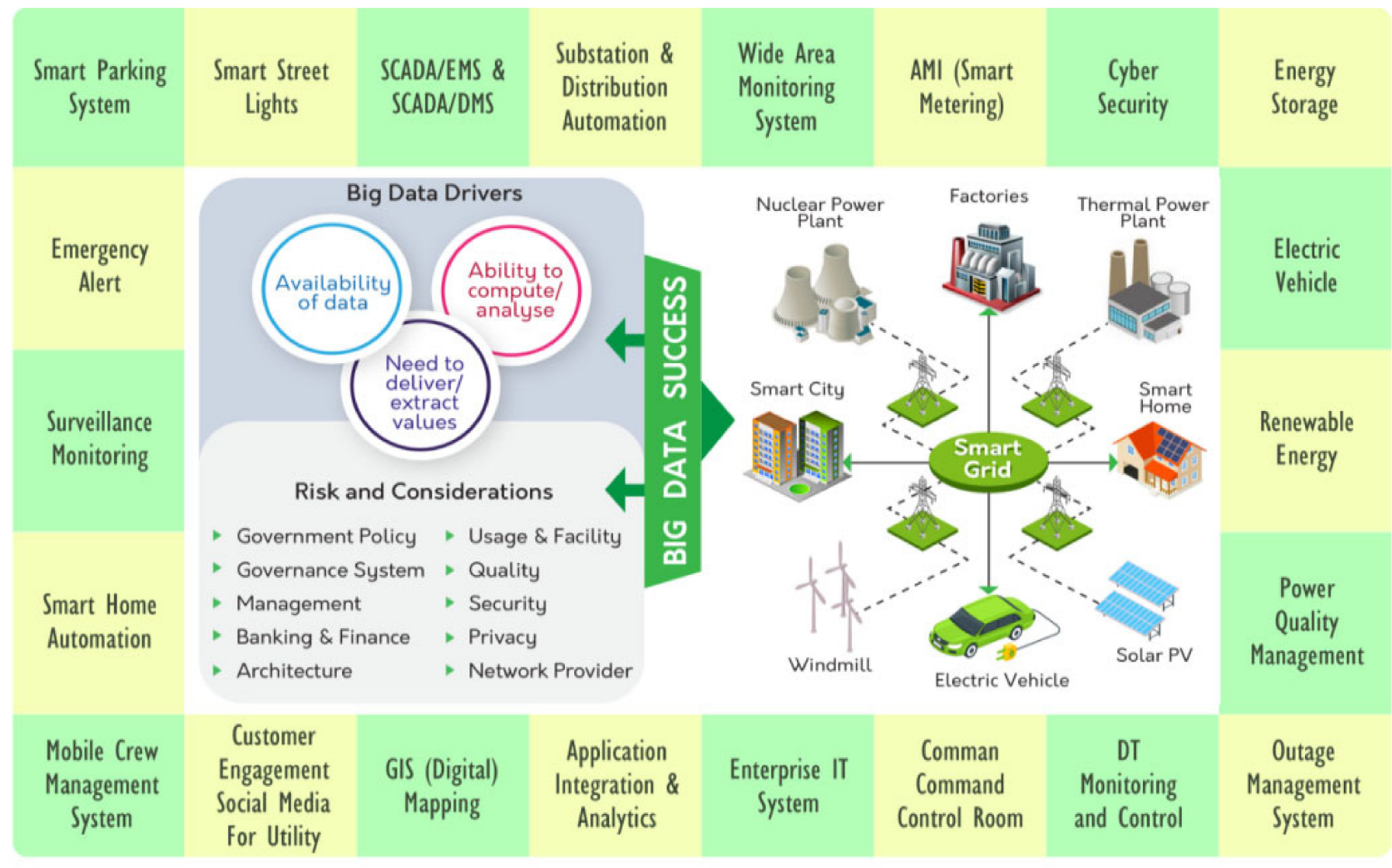

SCADA - Supervisory Control And Data Acquisition; EMS - Energy Management System; DMS - Distribution Management System; AMI - Advance Metering Infrastructure; DI - Distribution Transformer, GIS - Geographic Information System

Figure 6. Big data in smart grid management systems. 
This characteristic enables the smart grid to supply power received from widely distributed sources such as solar power systems, wind turbines and hybrid EVs [62]. The smart grid monitors the substations and controls the non-critical and critical operational data, for instance, breaker, transformer status, power factor performance, power status, security, etc., as represented in Figure 6. It also shows that Programmable Logic Controller (PLC), wireless, cellular, SCADA (Supervisory Control and Data Acquisition) and Phasor Measurement Unit (PMU) are some of the technologies utilized in smart grid communications to determine the electrical signals travelling in the electricity grid. The time synchronizer enables simultaneous synchronized real-time measurements of multiple remote measurement points on the grid, which results in the collection of a sufficient volume of data for futher analysis [83].

Using big data analytics, the collected data is analysed and the results are helpful in forecasting safety-related issues in equipment connected with smart grids, as shown in Figure 7. It showcases a clear process and the role of big data analytics in determining the load limits, power outage and asset management in the smart grid. The information is collected from various sources such as social media, grid operations and consumers and assessed with smart grid information for better load management. Energy demand is forecasted by the smart grid using big data analytics based on the information retrieved from load curves. This information is a collective of energy production and distribution patterns of renewable energy in the grid [25].

\subsection{Big Data Analytics Process in the Smart Grid}

Figure 7 thoroughly explains the role of big data analytics in the smart grid with four questions. From Figure 7, the readers can get a clear view of big data analytics and how it is helpful for the smart grid to have efficient energy management. Table 3 explains the review questions and the role of big data analytics. The power generation optimization and peak load management depending on demand response offers economical benefits to the consumers. 




Figure 7. Real-time application of big data and analytics in the smart grid. 


\section{The Smart Grid with Big Data Analytics in Social, Economic, Technical and Policy Aspects to Achieve Sustainability}

Smart grids have multiple stakeholders, such as end users or consumers, utilities, governments, policy makers, regulators, technology vendors, environmentalists, utility employees and societies. Across the globe, novel Internet of Things (IoT) applications are utilized to provide smart and sustainable development to cities. It enables one to oversee, manage and control the devices, anywhere and anytime. Moreover, it helps one to gain insights and leverage real-time data for valuable inferences. The interconnections of energy storage and renewable energy with respect to society, cities and sustainabiltiy have been discussed in detail by researchers [84] to empower the smart grid. These authors intended to promote an integrated method by considering major influencing elements on socioeconomic, technical and environmental factors for the public policy system. Big data analytics must be leveraged here to manage both the transmission and distribution of the assets. Both information and historical data collected must be processed to forecast the load demand, operation and upcoming maintenance [85].

Smart grids underpin the establishment of smart cities with their efficient and reliable power. Further, its fast response through Information and Communication Technology (ICT) enhances the optimized utilization of energy in cities. Figure 8 is a comprehensive overview of integrating smart grids and sustainable cities in terms of underlying foundations and assumptions [84,85], research opportunities and horizons, emerging scientific and technological trends and future planning practices [86,87]. It also illustrates the achievement of sustainability through grid learning and efficient management of data with big data analytics in social, economic, technical and policy optimization by different authors $[88,89]$.

As shown in Figure 8, efficient energy utilization, integration of renewable energy sources, establishing electrical storage system, increased penetration of EVs for transport and energy storage, smart water and waste management, good sanitation and clean water and health care are the vital supporting pillars of a smart city. Being a pivotal component for a futuristic society, smart grids contribute towards the achievement of SDGs by entrenching smart cities. The smart grid helps in controlling and monitoring the distribution side efficiently. To reach this aim, appropriate infrastructure and technologies should be entrenched, while the applications should be scaled for consumers in order to witness favorable progress. The smart grid makes the Distributed Generations (DGs) completely compatible and heals by itself to provide affordable and quality power at an economicand environmentally-friendly mode [90]. Cloud platform and smart metering architecture are developed for this process to render a wide range of services for management and automation of next-gen distribution grids [91]. Smart grid technology has made a deep impact on SDGs.

\subsection{Big Data Analytics' Role in the Smart Grid to Achieve Sustainability}

The smart grid can be supportive to offer affordable and clean energy with better energy efficiency and the integration of renewable energy [92,93]. In other words, it can bolster the progress towards SDG 7 and other goals. The optimization of energy efficiency and dynamic load management is offered in the smart grid through monitoring, controlling and conserving the energy that paves the way towards achieving sustainability goals [94]. Table 4 shows a review of previous works to clarify how big data analytics, in the smart grid, helps in achieving sustainable goals.

In Table 4, a summary of the features, data management factors and challenges associated with data management of smart grids is provided. The authors also reviewed the primary concern, i.e., security risks and the solutions to mitigate or remove such risks. When it comes to future smart grids, the primary challenges would be information privacy, electric vehicle interfacing, demand forecasting, optimization and demand-side management. As shown in the table, the advantages bundled with a smart grid are cheap energy conservation and peak load management; the latter can be attained using 
appropriate data in optimization techniques and communication technologies to critically analyse the requirements of a smart grid.



Figure 8. Achievement of sustainability with grid "smartization" and efficient management of data with big data analytics in social, economic, technical and policy aspects. 
Table 4. Specific information from literature on big data analytics in the smart grid to achieve sustainability.

\begin{tabular}{cc}
\hline Author \& Year & Objectives \\
\hline$[95]$ & $\begin{array}{c}\text { Big data analytics in data management } \\
\text { for energy presumption. Big data } \\
\text { analytics in energy management. }\end{array}$
\end{tabular}

[96] Big data analytics in data management for energy presumption.

\section{Outcomes}

The architectural pattern gathers energy data and distributes it to prosumers who generate, utilize, exchange and market renewable energy in order to enhance smart grid energy usage. Big data analytics in data management for energy presumption.

Smart electric grids are potential enough to improve their capabilities to boost smart grid activities and energy management flow.

Big data analytics can enhance the decision making on power-sharing and safety of power grids.

Empower consumers' interests through the use of a wide range of data for efficient operation of energy-related sources in order to ensure a sustainable energy environment.

[69] Big data analytics in energy management. Microgrid Energy management

Determine the system's ability to withstand power outages.

Consumer needs are important for efficient energy production and usage.

Enhances the perfection of assessing a day-ahead load to increase the dependability, control and administration of energy market operations.

With the integration of distributed resources and instabilities in load periodicity, it is vital to forecast a realistic cost for efficient generation scheduling and operation, while reducing power losses in the smart grid.

To promote sustainable smart manufacturing, big data analytics should be used throughout the product lifetime.
In complex management situations, industry leaders should be assisted in making smart business decisions.

\subsection{Smart Grid Sustainability in Connection with the Achievement of SDGs}

From the discussions made above, it is clear that when big data analytics are employed in the smart grid, it helps the prosumers to have a better renewable energy market, informed decision making on power-sharing, the safety of power grids and better energy management. It also has load and energy forecasts with realistic costs for optimal generation scheduling and operation in the smart grid, while lowering power losses and greenhouse gas emissions. Finally, it provides everyone with affordable, dependable and clean energy. It also improves the perfect assessment of day load demands to increase the dependability, control and administration of energy market operations, which in turn increases decent work and economic growth. When the connections among numerous SDG targets are identified, it can help as a combination of various sectoral programmes and the establishment of integrated cross-sectoral policies to explore opportunities [100].

SDG 7 creates an impact on other SDGs as well, namely, SDG 2 (no hunger) and SDG 1. In connection with SDG 6, reliable and modern energy is required to pump the water for drinking and wastewater treatment purposes, which reflect in SDG 6.1 and 6.3. SDG 7 also has more connectivity in terms of poverty elimination, access to sufficient food through revolution in agriculture, sustainable food production system and continuous availability of drinking water. Similarly, SDG 1 has a connection with SDG 7 in terms of access to modern and sustainable energy and increased energy efficiency, which are fundamental for poverty elimination. Similarly, SDG 7 impacts other SDGs such as SDG 3, SDG 8 (decent work and economic growth), SDG 11, SDG 12, SDG 14 (life below water) and SDG 15 (life on land) [101].

In SDG 3, SDG 7 has an influence on target 3.8 which intends to offer access to quality health care services with affordable and reliable energy. Further, target 3.9 is also correlated with SDG 7, i.e., reduction in infections and deaths due to hazardous gases, waste released from power generation stations and industries with efficient power generation 
and demand response management. In SDG 8, SDG 7 has its impact via target 8.2, i.e., reliable and continuous supply for the global population, which achieves a high level of economic productivity through diversification. In targets 8.4 and 8.5, SDG 7 offers a decent job and encourages the growth of micro and small-scale industries with the usage of renewable energy and modernised equipment. In SDG 11, SDG 7 has its impact in target 11.1, i.e., to ensure access to sustainable transport and special attention towards susceptible circumstances and natural disasters. SDG 7 has its impact in SDG 12 through target 12.2, that offers sustainable management with data monitoring and control upon big data analytics. Further, through target 12.3, i.e., efficient utilization of natural resources with the integration of renewable sources in the smart grid, SDG 7 has a considerable influence. In target 12.4, SDG 7 helps in waste management and intends to offer a healthy life. In SDG 13, SDG 7 is directly linked to the reduction of greenhouses emissions with increased and effective utilization of renewable energy which, in turn, aims to phase out the usage of fossil fuels [102,103].

\section{Big Data Analytics as Solutions to Achieve Sustainability in the Smart Grid}

Smart meters have become a mandatory component in the smart grid because they can measure and record the electricity usage of consumers, and they connect the energy supplier and consumer through communication technology. This provides consumers with better access to information and enables them to make more inclusive decisions on their usage of electricity. This results in minimized power wastage and long-term carbon and financial savings with mobile devices and web portals [90]. The advancements in the smart grid with big data will enable the investigation of demand and supply concerns through communication networks. The outcomes can provide an option for the deployment of renewable energy resources and energy storage devices that offer better home energy management, transactive energy, price design and personal services, as shown in Figure 9 [54].

Smart grids are vulnerable to cyber-attacks, since they are connected to numerous operational circumstances and standards via the internet. Smart metering technology is burgeoning as a result of real-time monitoring, prowess over smart grid architecture and its powerful anti-theft skills. These skills tend to improve network security and save money [104,105].

When massive amounts of data are processed, information is lost and optimal performance becomes hindered [106,107]. Hence, there should be a way to develop appropriate smart grid wireless communication protocols. This improvement is necessary due to significant packet loss of information induced by the radio controller interface. Through smart metres, the Home Area Network (HAN) of the smart grids integrates renewable energy sources and home appliances. HANs connect with NAN while the latter gets the information from them. NAN data are sent to utility data centres via WAN, which acts as a communication network $[107,108]$.

The threat induced from the energy theft and cyber security in the smart grids involved with communication systems has significant impacts on the power system. Communication technology should be advanced for smart grids to execute big data analytics. To secure the smart grid, a fuzzy cluster-based analytical method and reinforcement learning along with big data analytics integration will be supportive, allowing it to act as a real-time processing engine. The successful smart grid integration of renewable energy necessitates a high level of information, communication and collaboration [109].

Economic information such as GDP (Gross Domestic Product), CPI (Consumer Price Index), PMI (Purchase Managers Index), sales value and prosperity index is sourced from consumers, business and government, and should be analysed using a big data analytics tool. Data related to lectricity generation from various sourcees such as electrical load demand, output, power quality and temperature are collected from the utility industry, residential and commercial establishments to ensure safe and reliable power. Thus, big data analytics helps in the adoption and action of the smart grid as per consumer behaviour. The 
growing competition and new entrants complicate the access process concerning smoother operations using bulk data [110].


Figure 9. Smart meter and its impact on the smart grid.

Cyber security threats pose serious risks to all stakeholders and can cause economic loss and data privacy issues. The purpose of theft precedes the occurrence of theft, which is affected by self-control. Attitudes regarding stealing, normalisation of theft and views on theft behaviour control all influence theft intention. Environmental, organisational structure, society, administration and communication and corporate governance practises to prevent data theft, unfairness and work overload provide opportunity factors for employees to engage in data theft [111]. To solve this challenge, new cyber security procedures are needed to identify vulnerable locations in the smart grid and prevent power disruptions [112]. The data-driven approaches are ideal for complicated grids with large datasets. Reliably converting these vast datasets into useful big data analytics is a difficult task, and selecting suitable techniques, such as matric theory, which does not depend on model parameters, is often preferable [113,114].

Furthermore, big data analytics helps in demand evolution by destabilizing the cost revenue model and uncertainty due to changing regulations, goals and policy. In addition to the economic operations, the smart grid provides resilency for climatic variations with the integration of big data analytics. In other terms, smart grids decide the actions of power generation and demand based on the forecasted power as well as meteorological data that includes temperature, humidity and rainfall. Due to the improvements made in smart homes and the usage of renewable and EV, EV charging data such as current, voltage, charging rate, peak load demand data and the state of charge need to be collected for smart grid analytics. With the available data, the analyses are performed with high-performance 
computing devices such as cloud computing, fog computing, distributed computing and GPU computing for real-time big data analytics. The outcomes enable better data storage, networking, processing service and control systems for centralized monitoring. The smart grid system involves layer A as a physical layer while layer B as communication layer as shown in Figure 10. Hence, the multivariate data fusion from these layers, if handled efficiently, can help in achieving sustainable goals.

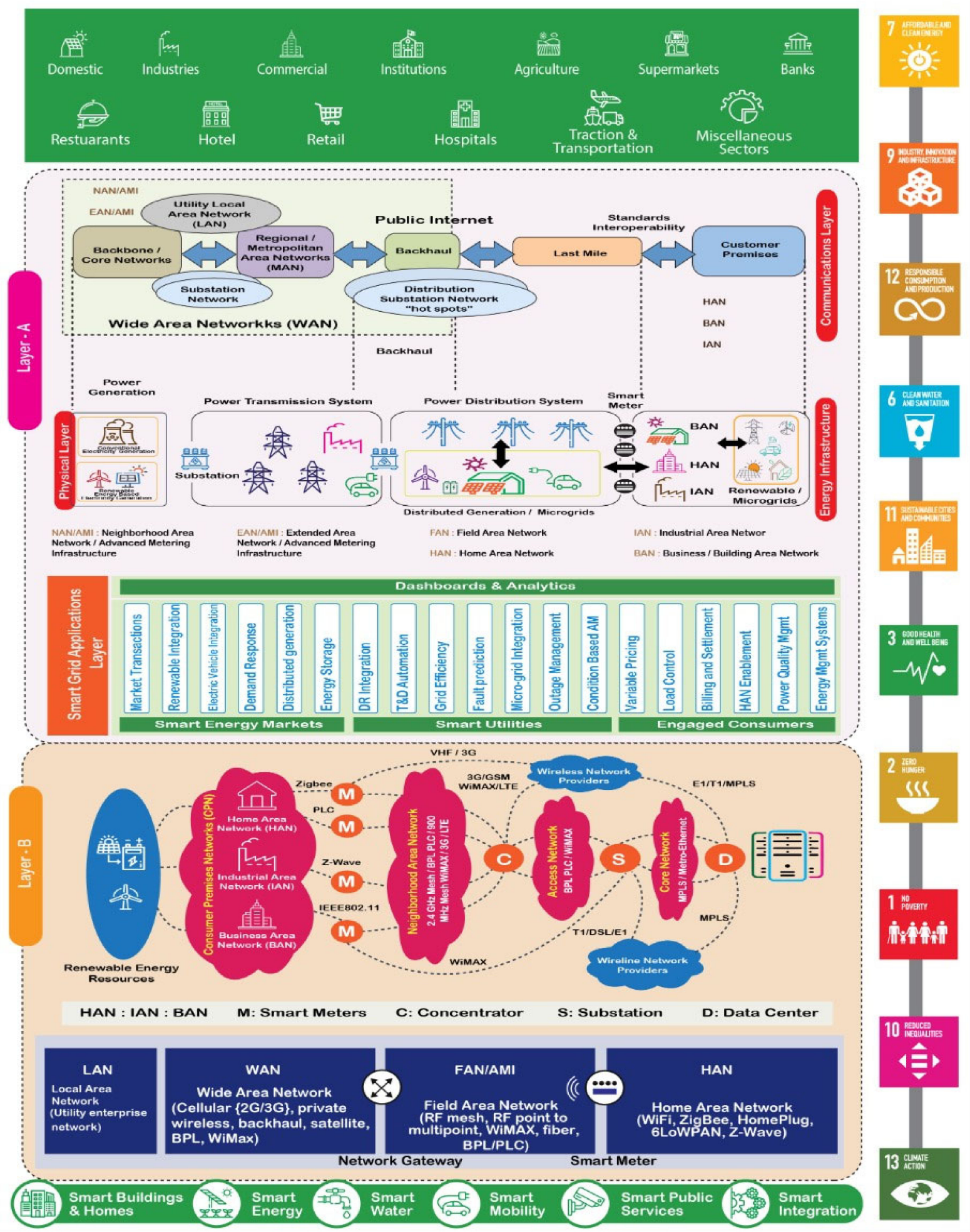

Figure 10. Prosumers in the smart grid with effective communication towards the achievement of sustainable goals. 
In the presence of complex power networks and with the increasing need for fast power balancing, it is critical to incorporate the data collected into the smart grid. Storage systems are becoming increasingly important in smart grids with renewable energy to preserve quality and uninterrupted energy in the residential, business, financial and public transportation sectors. Grid frequency regulation and control of renewable energy and energy storage penetration levels at the utility increase the consistency of the power system.

Smart grids can be turned into practical digital centres by involving several advanced operations such as the addition of renewable energy and energy storage systems to obtain environmental benefits [115]. Big data analytics architecture, as a solution in the smart grid, helps in locating results-oriented models. In the case of residential and public sectors, it helps in the reduction of energy consumption. Energy storage plays a major role in energy management, and the selection of high-density batteries with reduced size and cost improves the system's performance [116]. The suitable selection of battery storage system, optimization and life cycle assessment of the battery in the grid with big data analytics has a major impact on the reduction in greenhouse gases [117]. The cost involved with the integration of batteries in the grid is reduced by achieving a better life cycle and efficient charging mechanism [118].

These advanced operations are being performed with the aid of artificial intelligence and machine learning to create more informative systems. Initially, the demand response analysis supports the optimization of energy consumption by estimating the time of use, peak time, critical peak and real-time pricing and direct and remote load control. However, the aforementioned information generated from the energy systems needs to be communicated efficiently, without which the incorporated digital systems will become futile in function. The smart grid has various participants, such as domestic, industries, agriculture, public sectors, educational sectors, supermarkets, hospitals, private and public transportation, banks and measurements from grid [119]. Additionally, in recent times, the promotion of distributed energy resources for managing energy consumption has been embraced by governments and private sectors that emphasize social welfare, since smart grid solutions involved with such systems need better data analytics with intelligent systems as shown in Figure 11 [120].

Big data analytics are used in the energy industry to provide insights about the customer for transparency and simpler products. This is accomplished by analysing and predicting customer behaviour through data retrieved from social media, GPS-enabled devices and CCTV footage. Big data analytics allow better customer retention from insurance companies. Farmers need granular data on rainfall patterns, water cycles and fertilizer requirements, which empower them to make smart decisions for better profitability. In educational institutions and public sectors, the implementation of renewable energy sources helps in understanding the performance of an individual and at a collective level. Big data analytics in the commercial sector enable companies to create customer recommendations based on their purchase history. This suggestion results in personalized usage of energy experience and improved customer service. As a result, it can also help to improve revenue management, optimize marketing efforts and enhancing the delivery of customer service. Healthcare big data is inclusive of enormous volumes of information that are collected from digital technologies. These data are highly helpful in managing hospital performance since health care equipment is sensitive. Big data analytics help the public transportation sector to predict passenger volumes as precisely as possible. In this context, certain events such as bad weather, holidays, malfunctions and customer feedback from running transportation operations can be analysed and processed on a real-time basis [121]. All these automated systems and devices, with different applications, need efficient communication infrastructure in place for proper functioning. Further, the infrastructure should also allow remote control and regulation of the systems as and when needed. This is especially important in the case of controlling supply and demand, whether automated or manual. If one fails to control this balance, then it could potentially cause system overloads or area blackouts. Additionally, due to the critical nature of communication infrastructures and networks, 
it must be secured in the control centre system. Data theft, exploitation of authentication and attack on outdated elements, information theft, identity spoofing, eavesdropping and social engineering theft are possible attacks faced these days. Data security and privacy issues are magnified by the volume, variety and velocity of big data. However, there is a lack of a reference data model and data-related manipulation languages. Hence, the construction of an efficient communication network is inevitably an important factor [122].

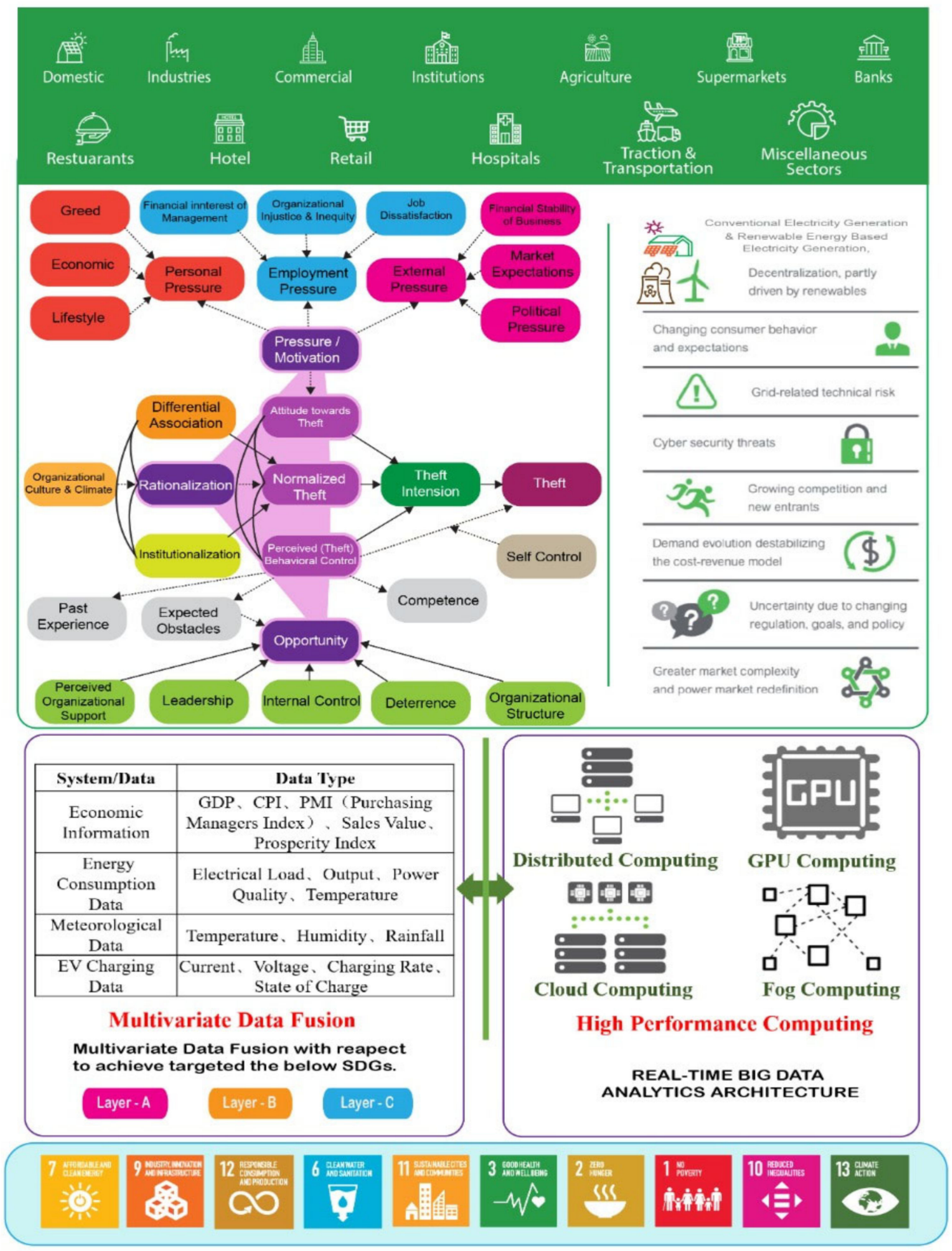

Figure 11. Sources of smart grid big data and energy theft monitoring with the real-time big data analytics architecture to attain the sustainable goals. 
AI techniques rely on huge volumes of data to construct autonomous systems that are capable of performing activities that would otherwise require human intelligence. Machine Learning (ML) is a subset of artificial intelligence, while ML and AI are involved with big data analytics-enabled decision making in which speed and accuracy are assured. In smart grid applications, Artificial Intelligence (AI) is described as the emulation of computers over the cognitive processes of the grid operators to gain self-healing capabilities [123]. Intelligent tools/mechanisms are needed to manage the system effectively and make timely decisions. The AI techniques are used in smart grids for better forecasting, networking, optimization and control strategies. In some circumstances, however, AI may not be able to replace grid operators. Although AI systems can be more exact, dependable and extensive, still, numerous obstacles exist to be overcome when using AI in a smart grid, as shown in Figure 12 [124,125].

Big data analytics along with machine learning techniques are essential to experience the benefits of efficient load forecasting and data acquisition techniques, along with costeffectiveness, in a smart grid. Since the smart grid involves the complex components connected the lead to the lack of security in information shared [126]. The improper and unpredictable situation of renewable energy also creates challenges in the smart grid. Hence, the forecasting of energy gains importance, and can be provided with the intelligent monitoring of machine learning. Among the different machine learning technologies, the artificial neural network performs better with the reliability and resilience of a smart grid [127]. For the efficient prediction of energy, big data and machine learning act as a suitable solution for energy management, which can potentially reduce energy cost and offer high quality of service and a healthier environment. Machine learning methods, such as artificial neural networks (ANNs), Random Forest (RF) and Support Vector Machine (SVM) can predict energy efficiency and the consumption of each energy resource [128]. The effective use of machine learning in the energy sector is expected to require data collecting, administration and security. Unsupervised and reinforcement learning are expected to play a crucial role in the energy sector, promoting the evolution of machine learning techniques for energy conservation, especially with big data analytics [129]. To improve system performance, deep neural networks (DNN) develop forecasting models, employing various techniques such as data analysis and text analytics. The data analytics feature is built using data mining techniques to obtain the information and discover trends that energy distributors need to make critical choices and efficiently handle their energy resources [130]. AI, along with machine learning techniques, can facilitate the achievement of 134 targets across all targets using a general agreement professional information gathering procedure, but it can also prevent the achievement of 59 targets. To enable long-term development, this technique must be accompanied by the required regulatory awareness [131].

Self-healing speed of the distribution network, reliability of power supply and safe functioning of the system offered by the big data analytics in a smart grid pave the way for equality. Also, the proposed system promotes renewable energy power generation, and the realization ratio of annual use hours result in a greener environment. The green power grid and green electricity are some of the benefits, since it reduces the area of unit amount of electricity, smart substation, electricity saved by power management and short-term profitability. Openness of power grid by investment in the open area of grid business, quality service evaluation index of quality service, integration effect of the grids, annual maximum load utilisation and EV utilisation rate are the merits of big data analytics. Finally, all these factors contribute to an efficient economy with low operating costs, where the efficient use of energy resources is encouraged through revenue from value-added services and enhanced grid infrastructure [132]. 


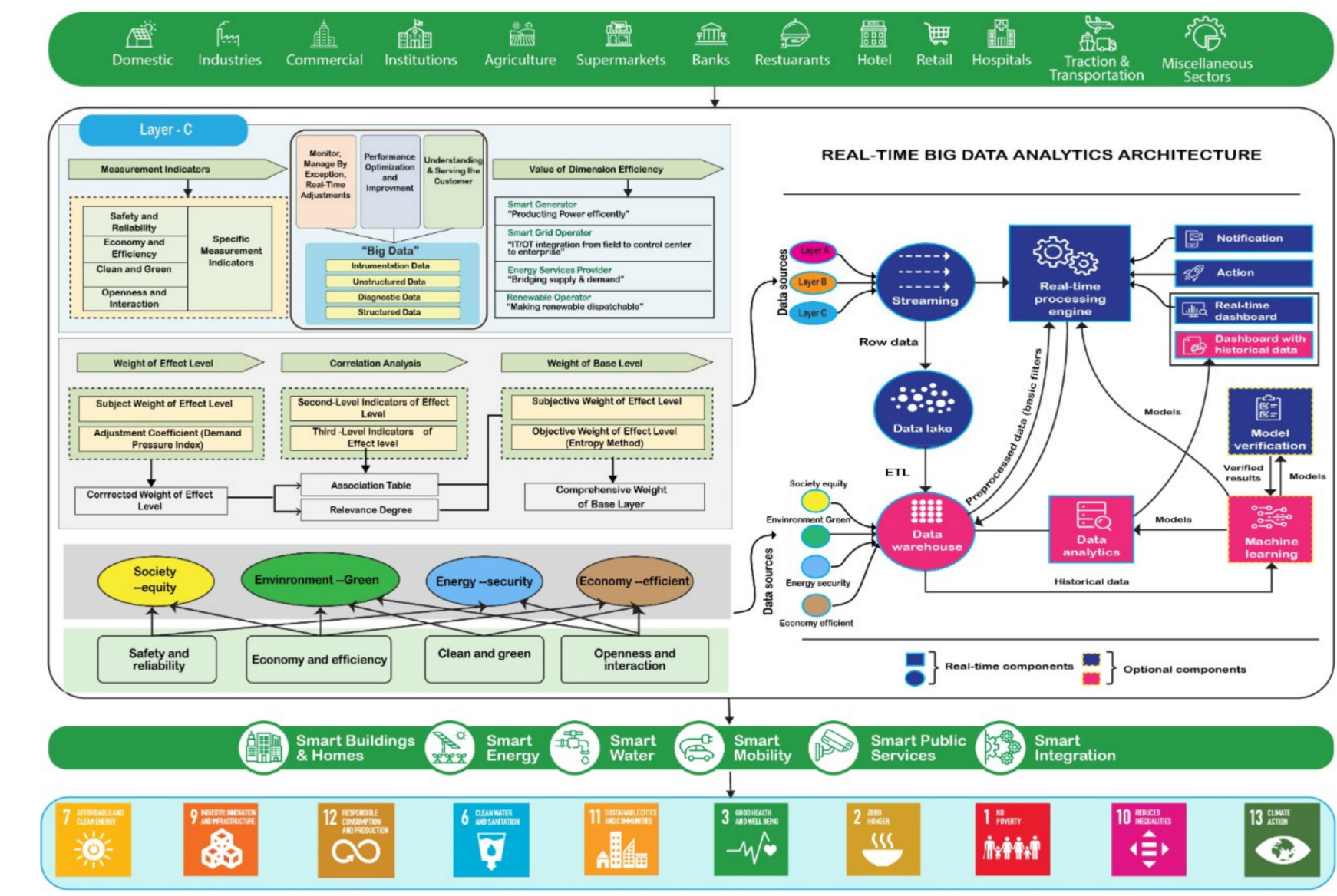

Figure 12. Real-time big data analytics in a smart grid achieve equity in society, green environment, secured energy and efficient economy with sustainable goals. 


\section{Challenges and Future Directions}

The real-time implementation of big data analytics in a smart grid along with efficient protocols will lead to challenges and issues in the future. Scalability, achieving a satisfactory and efficient method, data protection, reliable performance of the algorithm under unfavourable conditions and knowledge of artificial intelligence tools by the operators are certain constraints in achieving a sustainable future. To overcome these constraints and meet the needs of the future smart grid, certain significant research conundrums remain. Some of these difficulties are detailed below:

\subsection{Scaling of Testing Labs}

In smart grids, for deploying a huge number of smart meters, the utilities must check and update their meter testing facilities to evaluate these smart meters. These tools can process data from many inputs and provide valuable insights, for instance, back-end billing. The researchers must focus on exploring hardware and software availability to support smart grids for the right configuration. Investigations must also be conducted for efficient software development that can increase the trust among consumers. This can be achieved via the introduction of secured communication facilities with an intelligent system that offers efficient energy management and conservation to achieve a sustainable environment [132].

\subsection{Interoperability}

When smart grids with big data analytics are implemented globally, they pose a major concern in the area of interoperability. The absence of interoperability may prevent the investments that pour in and confine the synergies which result in costly redesigning of the smart grid. This reduces the benefits reaped. Therefore, proper investigations must be conducted in the areas of interoperability that can boost technology adoption through cost reduction and risk mitigation. There is no valuable research conducted so far in appropriate cloud computing services, especially in the case when there is no coordination between data usage and sharing. This scenario paves the way for the smart grid system to be efficient with interoperability among big data architecture, various devices, data analytics platforms, network operations, information models and data repositories [133].

\subsection{Data Analytics Innovation}

For efficient functioning of the power sector, flawless communication among utilities of distribution, transmission and generation with the market operator should exist, such that the information flow, scheduling data flow, operational data flow and commercial data flow occur without any shortcoming. An enormous amount of data plays a crucial role in energy accounting analysis, such as consumption pattern analysis, customer behaviour analysis, outage location and outage magnitude analysis, power demand analysis, quality and reliability analysis of supply, including voltage fluctuations and surges. Energy sectors and consumers can use artificial intelligence technology in descriptive, predictive and prescriptive analytics along with the machine learning concept. There is a need for efficient, scalable, self-organizing and adaptive platforms that can store and process big data in smart grids. This is one of the prominent solutions in the deployment of efficient distributed platforms [134].

\subsection{Data Privacy Innovation}

Smart grid implementation poses a major concern for customer privacy since it collects data about the consumer, e.g., Personally Identifiable Information (PII) and their energy consumption pattern. Therefore, investigations must be conducted in the domain of data aggregation to ensure privacy and make it impossible for anyone to access the data of consumers apart from the designated officials. Smart grids must be equipped with aggregation, encryption and steganography techniques to eliminate security challenges. 
The new technologies in the future must focus on data security, data collection limitations, reasonable storage, disposal methods and reliability [135].

\subsection{Need for Standards and Regulatory Frameworks}

Privacy notifications must be made in a precise, short and standard manner to make sure that the privacy practices are comprehended in a better way. Standard guidelines must be developed for data sharing by professionals across the communities. Regulatory frameworks should bind the utilities in the deployment of big data. This notice should contain all necessary and affiliating information about how the data is going to be used, duration of the usage and storage of data, purpose and the involvement of third parties with whom the data is shared. Regulatory compliance must be extensive enough to ensure the impact of big data applications is handled appropriately by taking cyber-security aspects into account $[136,137]$.

\subsection{Monitoring, Real-Time Control and Operation}

Based on the plan designed, the smart grid functions and performs throughout the year and is open to fine-tuning of the measures incorporated based on operational feedback. There are challenges with regards to scalability and computation when processing massive volumes of data. Thus, future researchers must focus on these areas. Criteria must be set to choose appropriate indicators and tools whenever the reliability and scalability of smart grids are assessed. This further enhances the advantages of the smart grid, thanks to the precise identification of savings through valuable feedback given on facility and operation [138].

\subsection{Innovative Computational Analytics}

The smart grid is a complicated environment with a wide range of optimization algorithms, spanning fundamental to optimization algorithms. Distributed and parallel intelligence are generally required to efficiently manage data computation and handling in smart grids. The development of appropriate computational analytics is the permanent solution that determines the consumption and production patterns. With the optimization difficulties, machine learning emerges as a critical tool. More research should be undertaken on selecting suitable machine learning and deep learning algorithms to make the smart grid system efficient.

\subsection{Integration with Advanced Visualization}

Visualization is not possible in the absence of existing schemes for smart energy big data analytics. Big data analytics primarily help the utilities to conduct their operations based on real-time situational intelligence and knowledge gained through data analytics. In such a scenario, advanced visualization must be integrated with data analytics. Being informative and instructive, the current analytics need the grid operators to make intuitive decisions. The operators are provided with excellent insights when the advanced visualization is integrated with automated operation. In this case, there is no need to have an intuition-based decision. Thus, a seamlessly integrated framework is nothing but an amalgamation of smart grid big data analytics and the upgraded visualization mechanisms that can mitigate the security risks and help in making informed decisions.

\section{Conclusions}

Smart grids, with efficient data analytics, predict the upcoming challenges in the event of unfavourable conditions that have an impact on economic, social and technical considerations. With the literature analysis from the previous works related to big data analytics in smart grids, the concepts, requirements and technologies involved are highlighted. The current paper details big data analytics in the smart grid and discusses how big data analytics are used in association with grid visualization as a future technology contribution towards the attainment of other SDGs. The current review's conclusion is 
summarized as follows: (i) Advancements in smart grid with big data analytics enable the investigation of demand and supply concerns through efficient communication networks; (ii)The smart grid involving public and private sector along with big data analytics encourages prosumers towards the achievement of sustainable goals; (iii) Big data analytics with the advanced computing technologies and energy theft monitoring help to attain the sustainable goals by economic operations based on real-time data obtained from the different sectors and consumer behaviour; (iv) Real-time big data analytics in the smart grid finally achieve equity in society, green environment, secured energy and an efficient economy, with artificial intelligence and machine learning technologies to promote the sustainable future.

The challenges and future directions were discussed with regards to the implementation and improvement of smart grid technologies with big data analytics to reduce energy poverty and greenhouse gas emissions for a sustainable environment. Therefore, the current study is expected to act as a standard guideline and authentic source for professionals and researchers who are going to study smart grid technology.

Author Contributions: Conceptualization, V.K.P., P.K.; methodology, V.K.P., P.K.; resources, R.M.E., V.R., R.K.A.; data curation, R.M.E., V.R., R.K.A.; writing-original draft preparation, V.K.P.; writingreview and editing, P.K., R.M.E.; visualization, R.M.E., P.K.; supervision, R.M.E., U.S., A.G., E.H. All authors have read and agreed to the published version of the manuscript.

Funding: This research received no external funding.

Institutional Review Board Statement: Not applicable.

Informed Consent Statement: Not applicable.

Data Availability Statement: Not applicable.

Acknowledgments: Not applicable.

Conflicts of Interest: The authors declare no conflict of interest.

\section{References}

1. Zhang, Q.; Liu, S.; Wang, T.; Dai, X.; Baninla, Y.; Nakatani, J.; Moriguchi, Y. Urbanization impacts on greenhouse gas (GHG) emissions of the water infrastructure in China: Trade-offs among sustainable development goals (SDGs). J. Clean. Prod. 2019, 232, 474-486. [CrossRef]

2. Zhou, N.; Zhang, J.; Khanna, N.; Fridley, D.; Jiang, S.; Liu, X. Intertwined impacts of water, energy development, and carbon emissions in China. Appl. Energy 2019, 238, 78-91. [CrossRef]

3. Schappert, M.; von Hauff, M. Sustainable consumption in the smart grid: From key points to eco-routine. J. Clean. Prod. 2020, 267, 121585. [CrossRef]

4. Baležentis, T.; Štreimikienè, D. Sustainability in the Electricity Sector through Advanced Technologies: Energy Mix Transition and Smart Grid Technology in China. Energies 2019, 12, 1142. [CrossRef]

5. Milchram, C.; Künneke, R.; Doorn, N.; van de Kaa, G.; Hillerbrand, R. Designing for justice in electricity systems: A comparison of smart grid experiments in the Netherlands. Energy Policy 2020, 147, 111720. [CrossRef]

6. Elsevier. The Power of Data to Advance the SDGs. In Mapping Research for the Sustainable Development Goals; SDG Resource Centre: London, UK, 2020.

7. Marcillo-Delgado, J.C.; Ortego, M.I.; Pérez-Foguet, A. A compositional approach for modelling SDG7 indicators: Case study applied to electricity access. Renew. Sustain. Energy Rev. 2019, 107, 388-398. [CrossRef]

8. Minas, H.; Tsutsumi, A.; Izutsu, T.; Goetzke, K.; Thornicroft, G. Comprehensive SDG goal and targets for non-communicable diseases and mental health. Int. J. Ment. Health Syst. 2015, 9, 12. [CrossRef]

9. Hák, T.; Janoušková, S.; Moldan, B. Sustainable Development Goals: A need for relevant indicators. Ecol. Indic. 2016, 60, 565-573. [CrossRef]

10. Salvia, A.L.; Leal Filho, W.; Brandli, L.L.; Griebeler, J.S. Assessing research trends related to Sustainable Development Goals: Local and global issues. J. Clean. Prod. 2019, 208, 841-849. [CrossRef]

11. Eisenmenger, N.; Pichler, M.; Krenmayr, N.; Noll, D.; Plank, B.; Schalmann, E.; Wandl, M.-T.; Gingrich, S. The Sustainable Development Goals prioritize economic growth over sustainable resource use: A critical reflection on the SDGs from a socioecological perspective. Sustain. Sci. 2020, 15, 1101-1110. [CrossRef]

12. Alaqeel, T.A.; Suryanarayanan, S. A comprehensive cost-benefit analysis of the penetration of Smart Grid technologies in the Saudi Arabian electricity infrastructure. Util. Policy 2019, 60, 100933. [CrossRef] 
13. Boardman, E. Advanced Applications in an Advanced Distribution Management System: Essentials for Implementation and Integration. IEEE Power Energy Mag. 2020, 18, 43-54. [CrossRef]

14. Zhou, S.; Zou, F.; Wu, Z.; Gu, W.; Hong, Q.; Booth, C. A smart community energy management scheme considering user dominated demand side response and P2P trading. Int. J. Electr. Power Energy Syst. 2020, 114, 105378. [CrossRef]

15. Puttamadappa, C.; Parameshachari, B.D. Demand side management of small scale loads in a smart grid using glow-worm swarm optimization technique. Microprocess Microsyst. 2019, 71, 102886. [CrossRef]

16. Giourka, P.; Sanders, M.W.J.L.; Angelakoglou, K.; Pramangioulis, D.; Nikolopoulos, N.; Rakopoulos, D.; Tryferidis, A.; Tzovaras, D. The Smart City Business Model Canvas-A Smart City Business Modeling Framework and Practical Tool. Energies 2019, 12, 4798. [CrossRef]

17. Radenković, M.; Bogdanović, Z.; Despotović-Zrakić, M.; Labus, A.; Lazarević, S. Assessing consumer readiness for participation in IoT-based demand response business models. Technol. Forecast Soc. Change 2020, 150, 119715. [CrossRef]

18. Chakraborty, R.; Samanta, A.; Agrawal, K.M.; Dutta, A. Towards smarter grid: Policy and its impact assessment through a case study. Sustain Energy. Grids Networks 2021, 26, 100436. [CrossRef]

19. Canha, L.N.; Adeyanju, O.M.; Ney, R.C.; Arend, G.; Zancan, D.N. The Roles of Customers, Utilities and Companies in Accelerating Smart Grid Implementation. In Proceedings of the 2019 IEEE PES Innovative Smart Grid Technologies Conference-Latin America (ISGT Latin America 2019), Gramado, Brazil, 15-18 September 2019; pp. 593-599. [CrossRef]

20. Zhou, K.; Fu, C.; Yang, S. Big data driven smart energy management: From big data to big insights. Renew. Sustain. Energy Rev. 2016, 56, 215-225. [CrossRef]

21. Syed, D.; Zainab, A.; Ghrayeb, A.; Refaat, S.S.; Abu-Rub, H.; Bouhali, O. Smart Grid Big Data Analytics: Survey of Technologies, Techniques, and Applications. IEEE Access 2021, 9, 59564-59585. [CrossRef]

22. Bhattarai, B.P.; Paudyal, S.; Luo, Y.; Mohanpurkar, M.; Cheung, K.; Tonkoski, R.; Hovsapian, R.; Myers, K.S.; Zhang, R.; Zhao, P.; et al. Big data analytics in smart grids: State-of-the-art, challenges, opportunities, and future directions. IET Smart Grid 2019, 2, 141-154. [CrossRef]

23. Zhang, Y.; Huang, T.; Bompard, E.F. Big data analytics in smart grids: A review. Energy Inform. 2018, 1, 8. [CrossRef]

24. Ghorbanian, M.; Dolatabadi, S.H.; Siano, P. Big Data Issues in Smart Grids: A Survey. IEEE Syst. J. 2019, 13, 4158-4168. [CrossRef]

25. Daki, H.; El Hannani, A.; Aqqal, A.; Haidine, A.; Dahbi, A. Big Data management in smart grid: Concepts, requirements and implementation. J. Big Data 2017, 4, 13. [CrossRef]

26. Alonso, M.; Amaris, H.; Alcala, D.; Florez, R.D.M. Smart Sensors for Smart Grid Reliability. Sensors 2020, 20, 2187. [CrossRef]

27. Veichtlbauer, A.; Heinisch, A.; von Tüllenburg, F.; Dorfinger, P.; Langthaler, O.; Pache, U. Smart Grid Virtualisation for Grid-Based Routing. Electronics 2020, 9, 1879. [CrossRef]

28. Ananthavijayan, R.; Karthikeyan Shanmugam, P.; Padmanaban, S.; Holm-Nielsen, J.; Blaabjerg, F.; Fedak, V. Software Architectures for Smart Grid System-A Bibliographical Survey. Energies 2019, 12, 1183. [CrossRef]

29. Qadir, Z.; Khan, S.I.; Khalaji, E.; Munawar, H.S.; Al-Turjman, F.; Mahmud, M.P.; Kouzani, A.Z.; Le, K. Predicting the energy output of hybrid PV-wind renewable energy system using feature selection technique for smart grids. Energy Rep. 2021, 7, 8465-8475. [CrossRef]

30. Ul Hassan, M.; Rehmani, M.H.; Kotagiri, R.; Zhang, J.; Chen, J. Differential privacy for renewable energy resources based smart metering. J. Parallel. Distrib. Comput. 2019, 131, 69-80. [CrossRef]

31. Sutherland, B.R. Securing Smart Grids with Machine Learning. Joule 2020, 4, 521-522. [CrossRef]

32. Kong, Q.; Fowler, M.; Entchev, E.; Ribberink, H.; McCallum, R. The Role of Charging Infrastructure in Electric Vehicle Implementation within Smart Grids. Energies 2018, 11, 3362. [CrossRef]

33. Stanelyte, D.; Radziukynas, V. Review of Voltage and Reactive Power Control Algorithms in Electrical Distribution Networks. Energies 2019, 13, 58. [CrossRef]

34. Bayer, B.; Marian, A. Innovative measures for integrating renewable energy in the German medium-voltage grids. Energy Rep. 2020, 6, 336-342. [CrossRef]

35. Hasan, A.N.; Tshivhase, N. Voltage regulation system for OLTC in distribution power systems with high penetration level of embedded generation. Int. Trans. Electr. Energy Syst. 2019, 29, e12111. [CrossRef]

36. Motyka, D.; Kajanová, M.; Braciník, P. The Impact of Embedded Generation on Distribution Grid Operation. In Proceedings of the 2018 7th International Conference on Renewable Energy Research and Applications (ICRERA), Paris, France, 14-17 October 2018; pp. 360-364. [CrossRef]

37. Ma, K.; Fang, L.; Kong, W. Review of distribution network phase unbalance: Scale, causes, consequences, solutions, and future research directions. CSEE J. Power Energy Syst. 2020, 6, 479-488. [CrossRef]

38. Islam, M.; Nadarajah, M.; Hossain, M.J. Dynamic voltage stability of unbalanced DNs with high penetration of roof-top PV units. Int. Trans. Electr. Energy Syst. 2020, 30, e12631. [CrossRef]

39. Joseph, T.; Ugalde-Loo, C.E.; Liang, J.; Coventry, P.F. Asset Management Strategies for Power Electronic Converters in Transmission Networks: Application to Hvdc and FACTS Devices. IEEE Access 2018, 6, 21084-21102. [CrossRef]

40. Weber, S.; Peters, J.F.; Baumann, M.; Weil, M.R. Life Cycle Assessment of a Vanadium Redox Flow Battery. Environ. Sci. Technol. 2018, 52, 10864-10873. [CrossRef] 
41. Zheng, Y.; Niu, S.; Shang, Y.; Shao, Z.; Jian, L. Integrating plug-in electric vehicles into power grids: A comprehensive review on power interaction mode, scheduling methodology and mathematical foundation. Renew. Sustain. Energy Rev. 2019, 112, 424-439. [CrossRef]

42. Hossain, E.; Tür, M.R.; Padmanaban, S.; Ay, S.; Khan, I. Analysis and Mitigation of Power Quality Issues in Distributed Generation Systems Using Custom Power Devices. IEEE Access 2018, 6, 16816-16833. [CrossRef]

43. Ren, S.; Zhang, Y.; Liu, Y.; Sakao, T.; Huisingh, D.; Almeida, C.M.V.B. A comprehensive review of big data analytics throughout product lifecycle to support sustainable smart manufacturing: A framework, challenges and future research directions. J. Clean. Prod. 2019, 210, 1343-1365. [CrossRef]

44. Van den Broek, T.; van Veenstra, A.F. Governance of big data collaborations: How to balance regulatory compliance and disruptive innovation. Technol. Forecast. Soc. Change 2018, 129, 330-338. [CrossRef]

45. Wilcox, T.; Jin, N.; Flach, P.; Thumim, J. A Big Data platform for smart meter data analytics. Comput. Ind. 2019, 105, 250-259. [CrossRef]

46. Asaad, M.; Ahmad, F.; Alam, M.S.; Sarfraz, M. Smart grid and Indian experience: A review. Resour. Policy 2019, 101499. [CrossRef]

47. Khuntia, S.R.; Rueda, J.L.; van der Meijden, M.A.M.M. Smart Asset Management for Electric Utilities: Big Data and Future BT-Asset Intelligence through Integration and Interoperability and Contemporary Vibration Engineering Technologies; Mathew, J., Lim, C.W., Ma, L., Sands, D., Cholette, M.E., Borghesani, P., Eds.; Springer International Publishing: Cham, Switzerland, 2019 ; pp. $311-322$.

48. Hoffmann, M.W.; Wildermuth, S.; Gitzel, R.; Boyaci, A.; Gebhardt, J.; Kaul, H.; Amihai, I.; Forg, B.; Suriyah, M.; Leibfried, T.; et al. Integration of Novel Sensors and Machine Learning for Predictive Maintenance in Medium Voltage Switchgear to Enable the Energy and Mobility Revolutions. Sensors 2020, 20, 2099. [CrossRef]

49. Cho, K.; Kim, S. Energy Performance Assessment According to Data Acquisition Levels of Existing Buildings. Energies 2019, 12, 1149. [CrossRef]

50. Talaat, M.; Alsayyari, A.S.; Alblawi, A.; Hatata, A.Y. Hybrid-cloud-based data processing for power system monitoring in smart grids. Sustain. Cities Soc. 2020, 55, 102049. [CrossRef]

51. Musleh, A.S.; Chen, G.; Dong, Z.Y. A Survey on the Detection Algorithms for False Data Injection Attacks in Smart Grids. IEEE Trans. Smart Grid 2020, 11, 2218-2234. [CrossRef]

52. Bos, K.; Gupta, J. Stranded assets and stranded resources: Implications for climate change mitigation and global sustainable development. Energy Res. Soc. Sci. 2019, 56, 101215. [CrossRef]

53. Worighi, I.; Maach, A.; Hafid, A.; Hegazy, O.; Van Mierlo, J. Integrating renewable energy in smart grid system: Architecture, virtualization and analysis. Sustain. Energy Grids Netw. 2019, 18, 100226. [CrossRef]

54. Zame, K.K.; Brehm, C.A.; Nitica, A.T.; Richard, C.L.; Schweitzer, G.D. Smart grid and energy storage: Policy recommendations. Renew. Sustain. Energy Rev. 2018, 82, 1646-1654. [CrossRef]

55. Yao, D.; Wen, M.; Liang, X.; Fu, Z.; Zhang, K.; Yang, B. Energy Theft Detection With Energy Privacy Preservation in the Smart Grid. IEEE Internet Things J. 2019, 6, 7659-7669. [CrossRef]

56. Singh Aujla, G.; Garg, S.; Batra, S.; Kumar, N.; You, I.; Sharma, V. DROpS: A demand response optimization scheme in SDN-enabled smart energy ecosystem. Inf. Sci. 2019, 476, 453-473. [CrossRef]

57. Shewale, A.; Mokhade, A.; Funde, N.; Bokde, N.D. An Overview of Demand Response in Smart Grid and Optimization Techniques for Efficient Residential Appliance Scheduling Problem. Energies 2020, 13, 4266. [CrossRef]

58. Kamalaldin, A.; Linde, L.; Sjödin, D.; Parida, V. Transforming provider-customer relationships in digital servitization: A relational view on digitalization. Ind. Mark. Manag. 2020, 89, 306-325. [CrossRef]

59. Bedi, G.; Venayagamoorthy, G.K.; Singh, R.; Brooks, R.R.; Wang, K.-C. Review of Internet of Things (IoT) in Electric Power and Energy Systems. IEEE Internet Things J. 2018, 5, 847-870. [CrossRef]

60. Kabalci, Y.; Kabalci, E.; Padmanaban, S.; Holm-Nielsen, J.B.; Blaabjerg, F. Internet of Things Applications as Energy Internet in Smart Grids and Smart Environments. Electronics 2019, 8, 972. [CrossRef]

61. Andoni, M.; Robu, V.; Flynn, D.; Abram, S.; Geach, D.; Jenkins, D.; McCallum, P.; Peacock, A. Blockchain technology in the energy sector: A systematic review of challenges and opportunities. Renew. Sustain. Energy Rev. 2019, 100, 143-174. [CrossRef]

62. Alladi, T.; Chamola, V.; Rodrigues, J.J.P.C.; Kozlov, S.A. Blockchain in Smart Grids: A Review on Different Use Cases. Sensors 2019, 19, 4862. [CrossRef]

63. Dileep, G. A survey on smart grid technologies and applications. Renew. Energy 2020, 146, 2589-2625. [CrossRef]

64. Pop, C.; Cioara, T.; Antal, M.; Anghel, I.; Salomie, I.; Bertoncini, M. Blockchain Based Decentralized Management of Demand Response Programs in Smart Energy Grids. Sensors 2018, 18, 162. [CrossRef]

65. Mahmud, K.; Khan, B.; Ravishankar, J.; Ahmadi, A.; Siano, P. An internet of energy framework with distributed energy resources, prosumers and small-scale virtual power plants: An overview. Renew. Sustain. Energy Rev. 2020, 127, 109840. [CrossRef]

66. Hossein Motlagh, N.; Mohammadrezaei, M.; Hunt, J.; Zakeri, B. Internet of Things (IoT) and the Energy Sector. Energies 2020, 13, 494. [CrossRef]

67. Farmanbar, M.; Parham, K.; Arild, Ø.; Rong, C. A Widespread Review of Smart Grids Towards Smart Cities. Energies 2019, 12, 4484. [CrossRef]

68. Espe, E.; Potdar, V.; Chang, E. Prosumer Communities and Relationships in Smart Grids: A Literature Review, Evolution and Future Directions. Energies 2018, 11, 2528. [CrossRef]

69. Marinakis, V. Big Data for Energy Management and Energy-Efficient Buildings. Energies 2020, 13, 1555. [CrossRef] 
70. Campagna, N.; Caruso, M.; Castiglia, V.; Miceli, R.; Viola, F. Energy Management Concepts for the Evolution of Smart Grids. In Proceedings of the 2020 8th International Conference on Smart Grid (icSmartGrid), Paris, France, 17-19 June 2020; pp. $208-213$. [CrossRef]

71. Marino, C.A.; Marufuzzaman, M. A microgrid energy management system based on chance-constrained stochastic optimization and big data analytics. Comput. Ind. Eng. 2020, 143, 106392. [CrossRef]

72. Lü, X.; Wu, Y.; Lian, J.; Zhang, Y.; Chen, C.; Wang, P.; Meng, L. Energy management of hybrid electric vehicles: A review of energy optimization of fuel cell hybrid power system based on genetic algorithm. Energy Convers. Manag. 2020, 205, 112474. [CrossRef]

73. Ahmadi, S.; Fakehi, A.H.; Vakili, A.; Moeini-Aghtaie, M. An optimization model for the long-term energy planning based on useful energy, economic and environmental pollution reduction in residential sector: A case of Iran. J. Build. Eng. 2020, $30,101247$. [CrossRef]

74. Mangla, S.K.; Luthra, S.; Jakhar, S.; Gandhi, S.; Muduli, K.; Kumar, A. A step to clean energy—Sustainability in energy system management in an emerging economy context. J. Clean. Prod. 2020, 242, 118462. [CrossRef]

75. Ponce-Jara, M.A.; Ruiz, E.; Gil, R.; Sancristóbal, E.; Pérez-Molina, C.; Castro, M. Smart Grid: Assessment of the past and present in developed and developing countries. Energy Strateg. Rev. 2017, 18, 38-52. [CrossRef]

76. Al-Nory, M.T. Optimal Decision Guidance for the Electricity Supply Chain Integration With Renewable Energy: Aligning Smart Cities Research With Sustainable Development Goals. IEEE Access 2019, 7, 74996-75006. [CrossRef]

77. Das, H.S.; Rahman, M.M.; Li, S.; Tan, C.W. Electric vehicles standards, charging infrastructure, and impact on grid integration: A technological review. Renew. Sustain. Energy Rev. 2020, 120, 109618. [CrossRef]

78. Kyriakopoulos, G.L.; Arabatzis, G. Electrical energy storage systems in electricity generation: Energy policies, innovative technologies, and regulatory regimes. Renew. Sustain. Energy Rev. 2016, 56, 1044-1067. [CrossRef]

79. Bastida, M.; Vaquero García, A.; Cancelo Márquez, M.; Olveira Blanco, A. Fostering the Sustainable Development Goals from an Ecosystem Conducive to the SE: The Galician's Case. Sustainability 2020, 12, 500. [CrossRef]

80. Nurunnabi, M.; Esquer, J.; Munguia, N.; Zepeda, D.; Perez, R.; Velazquez, L. Reaching the sustainable development goals 2030, energy efficiency as an approach to corporate social responsibility (CSR). GeoJournal 2020, 85, 363-374. [CrossRef]

81. Cerf, M.E. Sustainable Development Goal Integration, Interdependence, and Implementation: The Environment-EconomicHealth Nexus and Universal Health Coverage. Glob. Chall. 2019, 3, 1900021. [CrossRef]

82. Hernández-Callejo, L. A Comprehensive Review of Operation and Control, Maintenance and Lifespan Management, Grid Planning and Design, and Metering in Smart Grids. Energies 2019, 12, 1630. [CrossRef]

83. Hasan, M.K.; Ahmed, M.M.; Hashim, A.H.A.; Razzaque, A.; Islam, S.; Pandey, B. A Novel Artificial Intelligence Based Timing Synchronization Scheme for Smart Grid Applications. Wirel. Pers. Commun. 2020, 114, 1067-1084. [CrossRef]

84. Padmanathan, K.; Govindarajan, U.; Ramachandaramurthy, V.K.; Rajagopalan, A.; Pachaivannan, N.; Sowmmiya, U.; Padmanaban, S.; Holm-Nielsen, J.B.; Xavier, S.; Periasamy, S.K. A sociocultural study on solar photovoltaic energy system in India: Stratification and policy implication. J. Clean. Prod. 2019, 216, 461-481. [CrossRef]

85. Dhupia, B.; Usha Rani, M.; Alameen, A. The Role of Big Data Analytics in Smart Grid Management BT-Emerging Research in Data Engineering Systems and Computer Communications; Venkata Krishna, P., Obaidat, M.S., Eds.; Springer: Singapore, 2020; Volume 1054, pp. 403-412.

86. Celvakumaran, P.; Ramachandaramurthy, V.K.; Padmanaban, S.; Padmanathan, K.; Pouryekta, A.; Pasupuleti, J. Technical Constraints of Integrating Net Energy Metering from the Malaysian Perspective. In Proceedings of the 2018 IEEE PES Asia-Pacific Power and Energy Engineering Conference (APPEEC), Sabah, Malaysia, 7-10 October 2018; pp. 757-762. [CrossRef]

87. Padmanathan, K.; Govindarajan, U.; Ramachandaramurthy, V.K.; Selvi T., S.O. Multiple Criteria Decision Making (MCDM) Based Economic Analysis of Solar PV System with Respect to Performance Investigation for Indian Market. Sustainability 2017, 9, 820. [CrossRef]

88. Khatua, P.K.; Ramachandaramurthy, V.K.; Kasinathan, P.; Yong, J.Y.; Pasupuleti, J.; Rajagopalan, A. Application and assessment of internet of things toward the sustainability of energy systems: Challenges and issues. Sustain. Cities Soc. 2020, $53,101957$. [CrossRef]

89. Kim, T.H.; Ramos, C.; Mohammed, S. Smart City and IoT. Futur. Gener. Comput. Syst. 2017, 76, 159-162. [CrossRef]

90. Avancini, D.B.; Rodrigues, J.J.P.C.; Martins, S.G.B.; Rabêlo, R.A.L.; Al-Muhtadi, J.; Solic, P. Energy meters evolution in smart grids: A review. J. Clean. Prod. 2019, 217, 702-715. [CrossRef]

91. Pau, M.; Patti, E.; Barbierato, L.; Estebsari, A.; Pons, E.; Ponci, F.; Monti, A. A cloud-based smart metering infrastructure for distribution grid services and automation. Sustain. Energy Grids Netw. 2018, 15, 14-25. [CrossRef]

92. Elavarasan, R.M.; Shafuullah, G.M.; Sanjeevikumar Padmanaban Kumar, N.M.; Annam, A.; Vetrichelvan, A.M.; Mihet-popa, L.; Holm-Nielson, J.B. A Comprehensive Review on Renewable Energy Development, Challenges, and Policies of Leading Indian States with an International Perspective. IEEE Access 2020, 8, 74432-74457. [CrossRef]

93. Lawer, E.T.; Herbeck, J.; Flitner, M. Selective Adoption: How Port Authorities in Europe and West Africa Engage with the Globalizing 'Green Port' Idea. Sustainability 2019, 11, 5119. [CrossRef]

94. Corbett, J.; Wardle, K.; Chen, C. Toward a sustainable modern electricity grid: The effects of smart metering and program investments on demand-side management performance in the US electricity sector 2009-2012. IEEE Trans. Eng. Manag. 2018, 65, 252-263. [CrossRef] 
95. Anthony Jnr, B.; Abbas Petersen, S.; Ahlers, D.; Krogstie, J. API deployment for big data management towards sustainable energy prosumption in smart cities-a layered architecture perspective. Int. J. Sustain. Energy 2020, 39, 263-289. [CrossRef]

96. Renugadevi, N.; Saravanan, S.; Naga Sudha, C.M. IoT based smart energy grid for sustainable cites. Mater. Today Proc. 2021. [CrossRef]

97. Safhi, H.M.; Frikh, B.; Ouhbi, B. Energy load forecasting in big data context. In Proceedings of the 2020 th International Conference on Renewable Energies for Developing Countries (REDEC), Marrakech, Morocco, 24-26 March 2020; pp. 1-6. [CrossRef]

98. Mujeeb, S.; Javaid, N.; Ilahi, M.; Wadud, Z.; Ishmanov, F.; Afzal, M. Deep Long Short-Term Memory: A New Price and Load Forecasting Scheme for Big Data in Smart Cities. Sustainability 2019, 11, 987. [CrossRef]

99. Adil, M.; Javaid, N.; Daood, N.; Asim, M.; Ullah, I.; Bilal, M. Big Data Based Electricity Price Forecasting Using Enhanced Convolutional Neural Network in the Smart Grid BT-Web, Artificial Intelligence and Network Applications; Barolli, L., Amato, F., Moscato, F., Enokido, T., Takizawa, M., Eds.; Springer International Publishing: Cham, Switzerland, 2020; pp. 1189-1201.

100. Bisaga, I.; Parikh, P.; Tomei, J.; To, L.S. Mapping synergies and trade-offs between energy and the sustainable development goals: A case study of off-grid solar energy in Rwanda. Energy Policy 2021, 149, 112028. [CrossRef]

101. Mainali, B.; Luukkanen, J.; Silveira, S.; Kaivo-oja, J. Evaluating Synergies and Trade-Offs among Sustainable Development Goals (SDGs): Explorative Analyses of Development Paths in South Asia and Sub-Saharan Africa. Sustainability 2018, 10, 815. [CrossRef]

102. Kumar, N.M.; Chopra, S.S.; Chand, A.A.; Elavarasan, R.M.; Shafiullah, G.M. Hybrid Renewable Energy Microgrid for a Residential Community: A Techno-Economic and Environmental Perspective in the Context of the SDG7. Sustainability 2020, 12, 3944. [CrossRef]

103. Mwasilu, F.; Justo, J.J.; Kim, E.-K.; Do, T.D.; Jung, J.-W. Electric vehicles and smart grid interaction: A review on vehicle to grid and renewable energy sources integration. Renew. Sustain. Energy Rev. 2014, 34, 501-516. [CrossRef]

104. Kimani, K.; Oduol, V.; Langat, K. Cyber security challenges for IoT-based smart grid networks. Int. J. Crit. Infrastruct. Prot. 2019, 25, 36-49. [CrossRef]

105. Wang, Y.; Chen, Q.; Kang, C. Overview of Smart Meter Data Analytics BT—Smart Meter Data Analytics: Electricity Consumer Behavior Modeling, Aggregation, and Forecasting; Wang, Y., Chen, Q., Kang, C., Eds.; Springer: Singapore, 2020; pp. 1-35. [CrossRef]

106. Saleem, Y.; Crespi, N.; Rehmani, M.H.; Copeland, R. Internet of Things-Aided Smart Grid: Technologies, Architectures, Applications, Prototypes, and Future Research Directions. IEEE Access 2019, 7, 62962-63003. [CrossRef]

107. Vinoth Kumar, P.; Venkata Ravindra, K.; Kumar, T.N.V.L. Smart Grid on Issues and Challenges. Int. J. Recent. Technol. Eng. 2019, $8,4628-4632$.

108. Hameed, Z.; Ahmad, F.; ur Rehman, S.; Ghafoor, Z. IoT Based Communication Technologies to Integrate and Maximize the Efficiency of Renewable Energy Resources with Smart Grid. In Proceedings of the 2020 International Conference on Computing and Information Technology (ICCIT-1441), Pattaya, Thailand, 14-15 May 2020; pp. 1-5. [CrossRef]

109. Wu, J.; Ota, K.; Dong, M.; Li, J.; Wang, H. Big Data Analysis-Based Security Situational Awareness for Smart Grid. IEEE Trans. Big Data 2016, 4, 408-417. [CrossRef]

110. Colmenar-Santos, A.; Muñoz-Gómez, A.M.; Rosales-Asensio, E.; López-Rey, Á. Electric vehicle charging strategy to support renewable energy sources in Europe 2050 low-carbon scenario. Energy 2019, 183, 61-74. [CrossRef]

111. Sharma, T.; Pandey, K.K.; Punia, D.K.; Rao, J. Of pilferers and poachers: Combating electricity theft in India. Energy Res. Soc. Sci. 2016, 11, 40-52. [CrossRef]

112. Chen, J.; Mohamed, M.A.; Dampage, U.; Rezaei, M.; Salmen, S.H.; Obaid, S.A.; Annuk, A. A Multi-Layer Security Scheme for Mitigating Smart Grid Vulnerability against Faults and Cyber-Attacks. Appl. Sci. 2021, 11, 9972. [CrossRef]

113. He, X.; Chu, L.; Qiu, R.C.; Ai, Q.; Ling, Z. A Novel Data-Driven Situation Awareness Approach for Future Grids-Using Large Random Matrices for Big Data Modeling. IEEE Access 2018, 6, 13855-13865. [CrossRef]

114. He, X.; Ai, Q.; Qiu, R.C.; Huang, W.; Piao, L.; Liu, H. A Big Data Architecture Design for Smart Grids Based on Random Matrix Theory. IEEE Trans. Smart Grid 2017, 8, 674-686. [CrossRef]

115. Mohr, M.; Peters, J.F.; Baumann, M.; Weil, M. Toward a cell-chemistry specific life cycle assessment of lithium-ion battery recycling processes. J. Ind. Ecol. 2020, 24, 1310-1322. [CrossRef]

116. Peters, J.F.; Baumann, M.; Zimmermann, B.; Braun, J.; Weil, M. The environmental impact of Li-Ion batteries and the role of key parameters-A review. Renew. Sustain. Energy Rev. 2017, 67, 491-506. [CrossRef]

117. Baumann, M.; Peters, J.F.; Weil, M.; Grunwald, A. $\mathrm{CO}_{2}$ Footprint and Life-Cycle Costs of Electrochemical Energy Storage for Stationary Grid Applications. Energy Technol. 2017, 5, 1071. [CrossRef]

118. Peters, J.; Buchholz, D.; Passerini, S.; Weil, M. Life cycle assessment of sodium ion batteries. Energy Environ. Sci 2016, 9, $1744-1751$. [CrossRef]

119. Sivarajah, U.; Kamal, M.M.; Irani, Z.; Weerakkody, V. Critical analysis of Big Data challenges and analytical methods. J. Bus. Res. 2017, 70, 263-286. [CrossRef]

120. Mohamed, M.A.; Mirjalili, S.; Dampage, U.; Salmen, S.H.; Obaid, S.A.; Annuk, A. A Cost-Efficient-Based Cooperative Allocation of Mining Devices and Renewable Resources Enhancing Blockchain Architecture. Sustainability 2021, 13, 10382. [CrossRef]

121. Kauffmann, E.; Peral, J.; Gil, D.; Ferrández, A.; Sellers, R.; Mora, H. A framework for big data analytics in commercial social networks: A case study on sentiment analysis and fake review detection for marketing decision-making. Ind. Mark. Manag. 2020, 90, 523-537. [CrossRef] 
122. Kang, C.; Wang, Y.; Xue, Y.; Mu, G.; Liao, R. Big Data Analytics in China's Electric Power Industry: Modern Information, Communication Technologies, and Millions of Smart Meters. IEEE Power Energy Mag. 2018, 16, 54-65. [CrossRef]

123. Chehri, A.; Fofana, I.; Yang, X. Security Risk Modeling in Smart Grid Critical Infrastructures in the Era of Big Data and Artificial Intelligence. Sustainability 2021, 13, 3196. [CrossRef]

124. Kotsiopoulos, T.; Sarigiannidis, P.; Ioannidis, D.; Tzovaras, D. Machine Learning and Deep Learning in smart manufacturing: The Smart Grid paradigm. Comput Sci. Rev. 2021, 40, 100341. [CrossRef]

125. Li, J.; Li, T.; Han, L. Research on the Evaluation Model of a Smart Grid Development Level Based on Differentiation of Development Demand. Sustainability 2018, 10, 4047. [CrossRef]

126. Hossain, E.; Khan, I.; Un-Noor, F.; Sikander, S.S.; Sunny, M.S.H. Application of Big Data and Machine Learning in Smart Grid, and Associated Security Concerns: A Review. IEEE Access 2019, 7, 13960-13988. [CrossRef]

127. Kanase-Patil, A.B.; Kaldate, A.P.; Lokhande, S.D.; Panchal, H.; Suresh, M.; Priya, V. A review of artificial intelligence-based optimization techniques for the sizing of integrated renewable energy systems in smart cities. Environ. Technol. Rev. 2020, 9, 111-136. [CrossRef]

128. Zekić-Sušac, M.; Mitrović, S.; Has, A. Machine learning based system for managing energy efficiency of public sector as an approach towards smart cities. Int. J. Inf. Manag. 2021, 58, 102074. [CrossRef]

129. Daniel Rangel-Martinez KDPNigam Luis, A. Ricardez-Sandoval, Machine learning on sustainable energy: A review and outlook on renewable energy systems, catalysis, smart grid and energy storage. Chem. Eng. Res. Des. 2021, 174, 414-441.

130. Jamil, F.; Iqbal, N.; Ahmad, S.; Kim, D. Peer-to-Peer Energy Trading Mechanism Based on Blockchain and Machine Learning for Sustainable Electrical Power Supply in Smart Grid. IEEE Access 2021, 9, 39193-39217. [CrossRef]

131. Vinuesa, R.; Azizpour, H.; Leite, I. The role of artificial intelligence in achieving the Sustainable Development Goals. Nat. Commun. 2020, 11, 233. [CrossRef]

132. Chakraborty, S.; Das, S.; Sidhu, T.; Siva, A.K. Smart meters for enhancing protection and monitoring functions in emerging distribution systems. Int. J. Electr. Power Energy Syst. 2021, 127, 106626. [CrossRef]

133. Ayadi, F.; Colak, I.; Bayindir, R. Interoperability in Smart Grid. In Proceedings of the 2019 7th International Conference on Smart Grid (icSmartGrid), Newcastle, Australia, 9-11 December 2019; pp. 165-169. [CrossRef]

134. Wang, Y.; Chen, Q.; Hong, T.; Kang, C. Review of Smart Meter Data Analytics: Applications, Methodologies, and Challenges. IEEE Trans. Smart Grid 2019, 10, 3125-3148. [CrossRef]

135. Jolfaei, A.; Kant, K. A lightweight integrity protection scheme for low latency smart grid applications. Comput. Secur 2019, 86, 471-483. [CrossRef]

136. Leszczyna, R. Standards on cyber security assessment of smart grid. Int. J. Crit. Infrastruct. Prot. 2018, 22, 70-89. [CrossRef]

137. Gifty, R.; Bharathi, R.; Krishnakumar, P. Privacy and security of big data in cyber physical systems using Weibull distribution-based intrusion detection. Neural Comput. Appl. 2019, 31, 23-34. [CrossRef]

138. Bansal, G.; Dua, A.; Aujla, G.S.; Singh, M.; Kumar, N. SmartChain: A Smart and Scalable Blockchain Consortium for Smart Grid Systems. In Proceedings of the 2019 IEEE International Conference on Communications Workshops (ICC Workshops), Shanghai, China, 22-24 May 2019; pp. 1-6. [CrossRef] 